\title{
Ginsenoside Rg1 Ameliorates Behavioral Abnormalities and Modulates the Hippocampal Proteomic Change in Triple Transgenic Mice of Alzheimer's Disease
}

\author{
Lulin Nie, ${ }^{1}$ Junxia Xia, ${ }^{2}$ Honglian Li, ${ }^{3}$ Zaijun Zhang, ${ }^{4}$ Ying Yang, ${ }^{5}$ Xinfeng Huang, \\ Zhendan He, ${ }^{6}$ Jianjun Liu, ${ }^{1}$ and Xifei Yang ${ }^{1}$
}

${ }^{1}$ Key Laboratory of Modern Toxicology of Shenzhen, Shenzhen Center for Disease Control and Prevention, Shenzhen 518055, China

${ }^{2}$ Department of Obstetrics, Shenzhen People's Hospital, The Second Clinical Medical College of Jinan University, Shenzhen 518020, China

${ }^{3}$ Department of Histology and Embryology, Tongji Medical College, Huazhong University of Science and Technology, Wuhan 430030, China

${ }^{4}$ Institute of New Drug Research and Guangzhou Key Laboratory of Innovative Chemical Drug Research in Cardio-cerebrovascular Diseases, Jinan University College of Pharmacy, Guangzhou 510632, China

${ }^{5}$ Department of Pathophysiology, Tongji Medical College, Huazhong University of Science and Technology, Wuhan 430070, China

${ }^{6}$ School of Pharmacy, Health Science Center, Shenzhen University, Shenzhen 518055, China

Correspondence should be addressed to Xifei Yang; xifeiyang@gmail.com

Received 15 May 2017; Revised 7 August 2017; Accepted 24 August 2017; Published 24 October 2017

Academic Editor: Juan M. Zolezzi

Copyright ( 2017 Lulin Nie et al. This is an open access article distributed under the Creative Commons Attribution License, which permits unrestricted use, distribution, and reproduction in any medium, provided the original work is properly cited.

\begin{abstract}
Alzheimer's disease (AD) is one of the most common neurodegenerative diseases, so far, there are no effective measures to prevent and cure this deadly condition. Ginsenoside Rg1 (Rg1) was shown to improve behavioral abnormalities in AD; however, the potential mechanisms remain unclear. In this study, we pretreated 7-month-old 3xTg-AD mice for 6 weeks with Rg1 and evaluated the effects of $\mathrm{Rg} 1$ on the behaviors and the protein expression of hippocampal tissues. The behavioral tests showed that $\operatorname{Rg} 1$ could improve the memory impairment and ameliorate the depression-like behaviors of 3xTg-AD mice. Proteomic results revealed a total of 28 differentially expressed hippocampal proteins between Rg1-treated and nontreated 3xTg-AD mice. Among these proteins, complexin-2 (CPLX2), synapsin-2 (SYN2), and synaptosomal-associated protein 25 (SNP25) were significantly downregulated in the hippocampus of $3 \mathrm{xTg}-\mathrm{AD}$ mice compared with the WT mice, and the treatment of Rg1 modulated the expression of CPLX2 and SNP25 in the hippocampus of 3xTg-AD mice. The expression of CPLX2, SYN2, and SNP25 was further validated by Western blot analysis. Taken together, we concluded that $\operatorname{Rg} 1$ could be a potential candidate drug to improve the behavioral deficits in $\mathrm{AD}$ via modulating the expression of the proteins (i.e., CPLX2, SYN2, and SNP25).
\end{abstract}

\section{Introduction}

Alzheimer's disease (AD) is an irreversible degenerative disease with brain dysfunction occurring among aged people, which is the main cause of dementia and affects $60 \%-65 \%$ of the world population $[1,2]$. According to the World Alzheimer Report 2016, the number of the patients with dementia is rapidly increasing due to aging. The report showed that there were 46.8 million people worldwide living with dementia in
2015 and this number will reach 131.5 million in 2050 [3]. Therefore, urgent effective treatment strategies against AD are desired.

The distinctive histopathological hallmarks of $\mathrm{AD}$ are extracellular senile plaques consisted of $\beta$-amyloid $(\mathrm{A} \beta)$ peptides, intracellular neurofibrillary tangles, neuronal loss, and synapse injury in some vulnerable regions such as the hippocampus [4-6]. In addition to cognitive impairment, neuropsychiatric symptoms such as depression-like behavior 
were prevalent in $\mathrm{AD}$ cases [7-10]. Although great advances have been achieved in the etiology of $\mathrm{AD}$, the mechanisms of neurodegenerative disease remain largely unclear.

Ginsenoside Rg1, a pharmacological active component purified from the natural product ginseng, could cross the blood-brain barrier (BBB) and had a positive effect on the brain [11]. Several studies revealed the neuroprotective properties of $\mathrm{Rg} 1$ in neurodegenerative diseases such as $\mathrm{AD}$ $[12,13]$. Rg1 could ameliorate cognitive impairment in the mouse model of $\mathrm{AD}$, improve the learning and memory abilities [14,15], decrease the levels of cerebral $\mathrm{A} \beta[16]$, maintain hippocampal neuron activity [17], and prevent cellular apoptosis induced by $\mathrm{A} \beta$ accumulation [18]. On the other hand, Rg1 also could protect against brain aging by enhancing the scavenging of free radicals in the brain [19]. However, the mechanisms underlying the protective effects of $\operatorname{Rg} 1$ against the behavioral abnormality and pathological changes are poorly understood.

In this study, we explored the effects of Rg1 treatment on memory and depression-like behaviors of 3xTg-AD mice and hippocampal proteome. It was worth mentioning that $3 \times \mathrm{Tg}$ $\mathrm{AD}$ mice displayed obvious memory impairment and anxiety and depression-like behavior $[20,21]$. By using twodimensional fluorescence differential gel electrophoresis (2D-DIGE) with mass spectrometry, we identified the differentially expressed proteins in the hippocampus of triple transgenic mice of $\mathrm{AD}(3 \times \mathrm{Tg}-\mathrm{AD})$ with or without administration of $\operatorname{Rg} 1$ and revealed the potential key molecules that may be involved in memory deficit and depression-like behaviors in $\mathrm{AD}$.

\section{Material and Methods}

2.1. Materials. Ginsenoside Rg1 was provided by Prof. Zhendan He, College of Life Sciences, Shenzhen University. The ginsenoside Rg1 was dissolved in saline and administered by intraperitoneal injection.

2.2. Animals and Treatment. The mice were purchased from Jackson Laboratory. In this study, we selected 7-month-old female $3 x T g-A D$ mice harboring $\mathrm{PS}_{\mathrm{M} 146 \mathrm{~V}}, \mathrm{APP}_{\text {Swe }}$, and $\mathrm{Tau}_{\mathrm{P} 301 \mathrm{~L}}$ transgenes (strain: $\mathrm{B} 6 ; 129-\mathrm{Psen} 1^{\mathrm{tm} 1 \mathrm{Mpm}} \mathrm{Tg}$ [APPSwe, tauP301L] 1Lfa/Mmjax) and WT (strain: B6129SF2/J) mice. The 7-month 3xTg-AD mice were treated with $\operatorname{Rg} 1(20 \mathrm{mg} / \mathrm{kg}$ body weight $)$ by intraperitoneal injection for 6 weeks [22]. In parallel, nontreated 3xTg-AD mice and WT mice were injected with saline. All animal experiments and procedures were approved by Shenzhen Center for Disease Control and Prevention. All efforts were made to minimize animal suffering and reduce the number of mice used.

2.3. Behavioral Evaluation. All the behavior tests were conducted in a quiet room, the experimental mice were transferred to the behavioral room $2 \mathrm{~h}$ before the assessment. In this study, the anxiety behavior of mice was tested by the open field test and the elevated plus maze test, the depression behavior of mice was tested by the tail suspension test, and the learning and memory ability of mice was measured by the Morris water maze test. The interval between tests was two days.

2.3.1. Open Field Test. The open field test was performed as previously described by Prut and Belzung [23]. The apparatus consisted of a brightly illuminated (120 lux) square arena of about $0.5 \mathrm{~m}$ width closed by a wall $0.45 \mathrm{~m}$ high. The whole arena was divided into 16 square areas $(12.5 \mathrm{~cm} \times 12.5 \mathrm{~cm})$. "Center" was consisted of four small squares of the center, and "corner" was made up of other squares. The camera was installed above the center of the device. Experimental mice were placed in the "center" and allowed to move freely in $5 \mathrm{~min}$. The degree of anxiety was assessed based on the activity time and distance of the mice in the center. The apparatus was cleaned with $75 \%$ ethanol solution between tests.

2.3.2. Elevated Plus Maze Test. The elevated plus maze test was performed as previously described by Belzung and Griebel [24]. It consisted of a cross of two closed arms $(50 \times 10 \mathrm{~cm})$ and two open arms $(50 \times 10 \mathrm{~cm})$. The mice were placed in the center and allowed to explore the maze for $5 \mathrm{~min}$. The lesser time and distance of the animals entering into open arms suggested that they were more anxious.

2.3.3. Tail Suspension Test. The tail suspension test was performed as previously described by Steru et al. [25]. Each mouse was suspended $50 \mathrm{~cm}$ above the floor for 5 min by sticking its tail. The mice were considered immobile only when they were fully motionless. In this study, the degree of depression was measured by the immobility ratio of mice.

2.3.4. Morris Water Maze Test. Morris water maze was performed as previously described by Deng-Bryant et al. [26]. It was used to evaluate spatial learning and memory of the mice. The water maze consisted of a circular pool $(1.7 \mathrm{~m}$ in diameter) filled with milk $\left(0.3 \mathrm{~m}\right.$ in depth, $\left.22^{\circ} \mathrm{C}\right)$ and a circular white escape platform $(0.1 \mathrm{~m}$ in diameter $)$ submerged $2 \mathrm{~cm}$ below the surface of the water. The water maze was subdivided into four quadrants (I-IV), the four quadrants were marked with triangular, circular, cross, and square, respectively. All the mice were trained for 5 consecutive days ( 4 trials /day) and the platform was in a fixed position. In the training stage, each mouse was given $60 \mathrm{~s}$ time to explore the platform, if the mice cannot find the platform within $60 \mathrm{~s}$, the experimenter led the mice to stay on the platform $15 \mathrm{~s}$. The latency of each mice was recorded. After 1 week, the mice were detected for $120 \mathrm{~s}$ without the platform in the pool. The swimming path was recorded by using the video tracking system.

2.4. Sample Preparation. The experimental mice were sacrificed after the behavioral tests. The bilateral hippocampus of mice was dissected on ice, and all samples were stored in $-80^{\circ} \mathrm{C}$. Samples were ultrasounded ( $3 \mathrm{~s}$ on, $5 \mathrm{~s}$ off for $3 \mathrm{~min}$ ) in lysis buffer $(7 \mathrm{M}$ urea, 2$)$, then the samples were centrifuged at $4^{\circ} \mathrm{C}, 12000 \mathrm{~g}$ for $1 \mathrm{~h}$. The protein solution discarded salts and impurities by ultrafiltration. The protein concentration was measured with 2-D Quant Kit (GE Healthcare, 


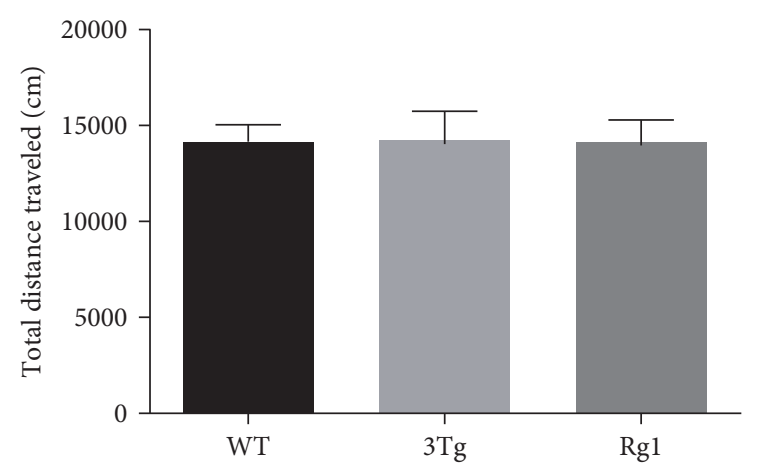

(a)

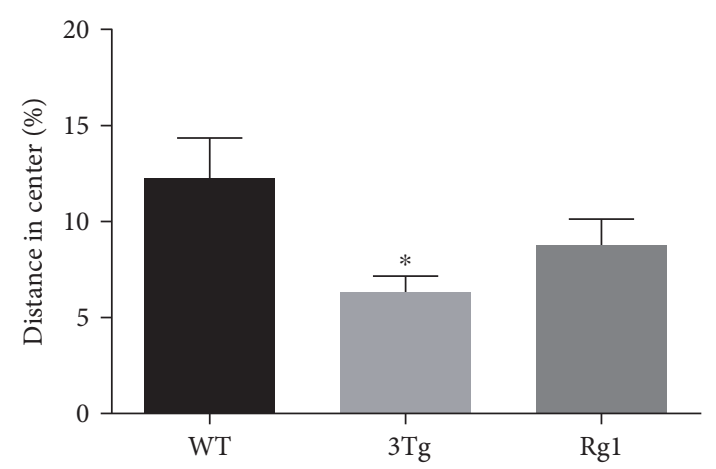

(b)

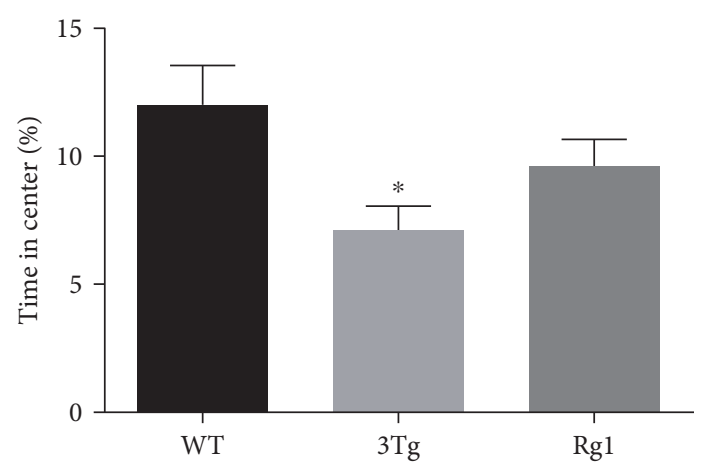

(c)

Figure 1: Anxiety-like behavior was measured by open field test. (a) Total distance traveled. (b) Distance traveled in the center of the open field. (c) Time spent in the center of the open field. The data were presented as mean \pm SEM. ${ }^{*} p<0.05$ versus WT mice. $n=10-15$ for each group.

USA). The samples $(\mathrm{pH}=8.5)$ were diluted to $5 \mu \mathrm{g} / \mu \mathrm{L}$ according to the protein quantification. All samples were stored in $-80^{\circ} \mathrm{C}$.

2.5. DIGE Labeling of Protein Samples. The DIGE labeling of protein samples was performed as previously by Iadevaia et al. [27]. Each CyDye dye was dissolved in $99.8 \%$ anhydrous N,N-dimethylformamide (DMF, Sigma 227056) to a final dye concentration of $1 \mathrm{nmol} / \mu \mathrm{L}$ as stock solution. The stock solution was diluted with DMF to $200 \mathrm{pmol} / \mu \mathrm{L}$ of working solution. The protein of differential group was treated with 200 pmol Cy3 (GE Healthcare, 25-8008-61) or Cy5 (GE Healthcare, 25-8008-62) dye markers for comparison on the same gel, and the internal standard was labeled with Cy2 (GE Healthcare, 25-8008-62). In brief, $25 \mu \mathrm{g}$ of each protein sample was labeled with $200 \mathrm{pmol}$ CyDyes on ice in the dark for $30 \mathrm{~min}$ and then quenched with $10 \mathrm{mmol}$ lysine (Sigma, L5626) for $10 \mathrm{~min}$. Then, the Cy5-, Cy3-, and Cy2labeled samples were mixed together, and each mixture was added with an equal volume of $2 \times$ lysis buffer ( $8 \mathrm{M}$ urea, $2 \%$ CHAPS, $0.2 \%$ DTT, $2 \%(v / v)$ IPG buffer, $\mathrm{pH} 3-11$ nonlinear, $0.002 \%$ bromophenol blue) and incubated on ice for $10 \mathrm{~min}$. The total volume of the sample was diluted to $450 \mu \mathrm{L}$ by adding hydration buffer.

2.6. Isoelectric Focusing and SDS-PAGE. The first-dimension isoelectric focusing (IEF) was performed using the Ettan IPGphor IEF system (GE Healthcare, USA). A total of
$75 \mu \mathrm{g}$ of each labeled samples was applied on a $24 \mathrm{~cm} \mathrm{pH}$ 3-11 NL Immobilized DryStrip (GE Healthcare). IEF was performed using the following conditions: $18 \mathrm{~h}$ at $50 \mathrm{~V}, 12 \mathrm{~h}$ at $300 \mathrm{~V}, 2 \mathrm{~h}$ at $500 \mathrm{~V}, 2 \mathrm{~h}$ at $1000 \mathrm{~V}$, and $8 \mathrm{~h}$ at $8000 \mathrm{~V}$. Each time, four or six IPG strips were run in parallel. After the first-dimension IEF, each strip was equilibrated for $15 \mathrm{~min}$ in the reducing equilibration buffer $(6 \mathrm{~mol} / \mathrm{L}$ urea, $30 \%$ $(v / v)$ glycerol, $75 \mathrm{mmol} / \mathrm{L}$ Tris-HCl buffer $(\mathrm{pH} 8.8), 2 \%$ $(w / v)$ SDS, and $1 \%(w / v)$ DTT) at room temperature. Subsequently, each strip was re-equilibrated in the similar buffer containing $4.5 \%$ iodoacetamide (IAA) instead of DTT for $15 \mathrm{~min}$. After the equilibration, each equilibrated strip was loaded on the top of $12.5 \%$ SDS-PAGE gels $(25 \mathrm{mM}$ Tris, $192 \mathrm{mM}$ glycine, $0.1 \%$ SDS, $0.02 \%$ bromophenol blue, $0.5 \%$ $(w / v)$ agarose) for the second dimension. Gels were run in Ettan DALTsix Electrophoresis System (GE Healthcare), and the electrophoresis was conducted under the following conditions: $1 \mathrm{~W} /$ gel for $1 \mathrm{~h}$ and $10 \mathrm{~W} / g e l$ for $5 \mathrm{~h}$ in the dark at $12^{\circ} \mathrm{C}$. Gels were immediately scanned using a Typhoon Trio Variable Mode Imager (GE Healthcare).

2.7. Image Analysis. Gel images were visualized by the Image Quant TL software. Differential proteins were analyzed using DeCyder TM 2D software (version 6.5 GE Healthcare) Differential In-gel Analysis (DIA) and Biological Variance Analysis (BVA) modules. The fluorescent intensity of each protein spot was determined in the Cy 3 or $\mathrm{Cy} 5$ channels and then normalized according to the corresponding 


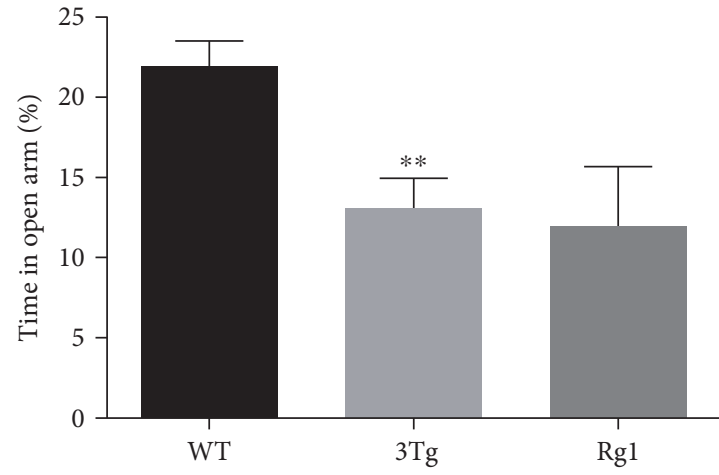

(a)

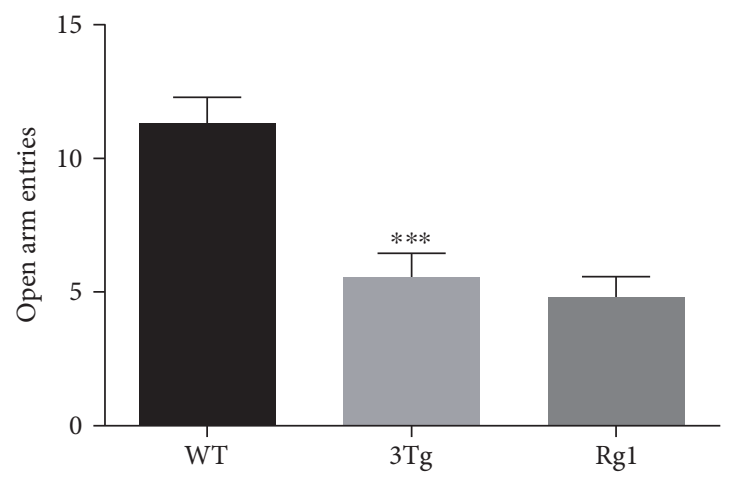

(c)

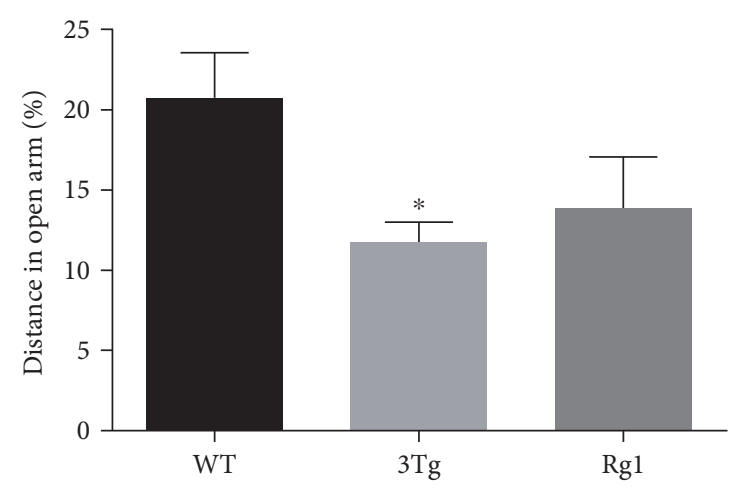

(b)

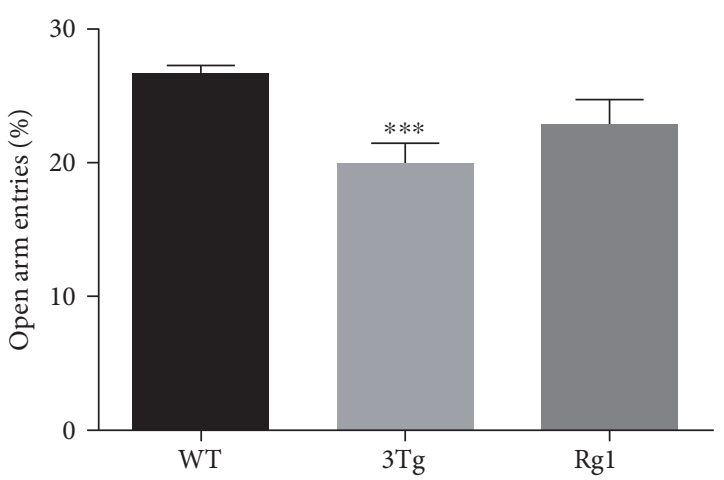

(d)

Figure 2: Anxiety-like behavior was measured by elevated plus maze test. (a) The percentage of the time spent in the open arms. (b) The percentage of the distance traveled in the open arms. (c) The number of entries into open arms. (d) The number of entries into open arms/number of entries to the open plus closed arms. The data were presented as mean \pm SEM. ${ }^{*} p<0.05,{ }^{* *} p<0.01$, and ${ }^{* * *} p<0.001$ versus WT mice. $n=10-15$ for each group.

fluorescent intensity of Cy2 spot. The normalized volume of a spot was compared across the gels between the replicate groups. The differential protein spots with significant difference $(p<0.05)$ were further analyzed.

2.8. In-Gel Digestion. A total of $1200 \mu \mathrm{g}$ of hippocampal protein was used to run 2-DE using the identical conditions as above. The gel was stained with Coomassie Brilliant Blue solution for $12 \mathrm{~h}$, then the gel was washed many times until the protein spots were visible. The differential protein spots with significant difference $(p<0.05)$ were manually excised from Coomassie blue staining gel. Subsequently, the protein spots were washed with deionized water and destained with $25 \mathrm{mmol} / \mathrm{L} \mathrm{NaHCO}_{3}$ solution $\left(50 \% \mathrm{ACN}, 50 \% \mathrm{H}_{2} \mathrm{O}\right.$ ) for $1 \mathrm{~h}$ at $37^{\circ} \mathrm{C}$. The spots were swollen and digested in a trypsin buffer (Promega Corp., WI, USA) for $12 \mathrm{~h}$ at $37^{\circ} \mathrm{C}$. Then, peptides were analyzed by MALDI-TOF-MS/MS.

2.9. Mass Spectrometry and Database Searching. Protein identification was analyzed by MALDI-TOF-MS/MS (AB SCIEX MALDI-TOF/TOF 5800 mass spectrometer). For the MADL-TOF-MS, $0.6 \mu \mathrm{L}$ of each sample peptide extraction was spotted on a stainless steel target and dried at room temperature, then each spot was crystallized with $1 \mu \mathrm{L} 50 \%$ acetonitrile $(\mathrm{ACN})$ and $0.1 \%$ trifluoroacetic acid (TFA) containing $10 \mathrm{mg} / \mathrm{mL} \quad \alpha$-cyano-4-hydroxycinnamic acid (CHCA) and dried at room temperature. After the

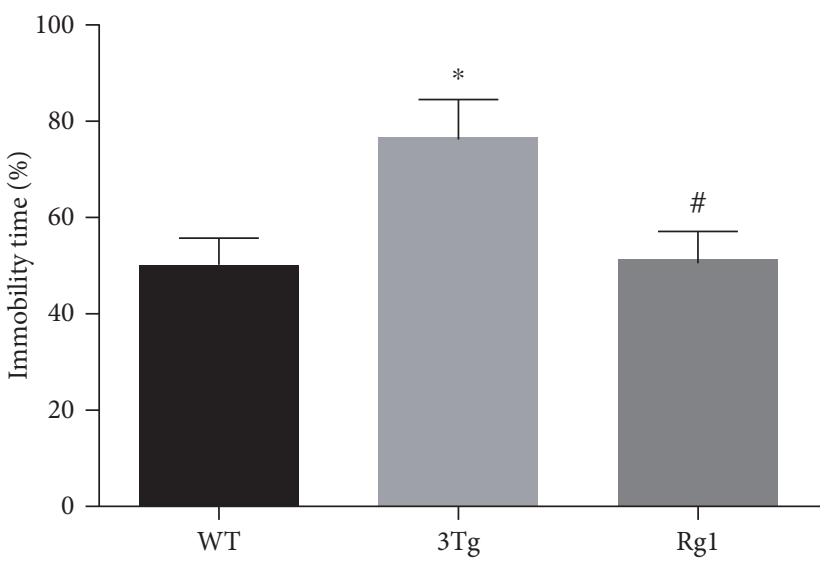

FIgURe 3: Depression-like behavior was measured by tail suspension test. The percentage of immobility time. The data were presented as mean \pm SEM. ${ }^{*} p<0.05$ versus WT mice; ${ }^{*} p<0.05$ versus $3 \mathrm{xTg}-\mathrm{AD}$ mice. $n=10-15$ for each group.

spectra were manually calibrated, database searching was carried out by MASCOT based on the SwissProt databases in Mus musculus. The search was performed with a tolerance on mass measurement of $100 \mathrm{ppm}$ in MS mode and $0.5 \mathrm{Da}$ in MS/MS mode. Protein $\mathrm{pI}$ and MW information were recorded to evaluate the identification of protein spots. 


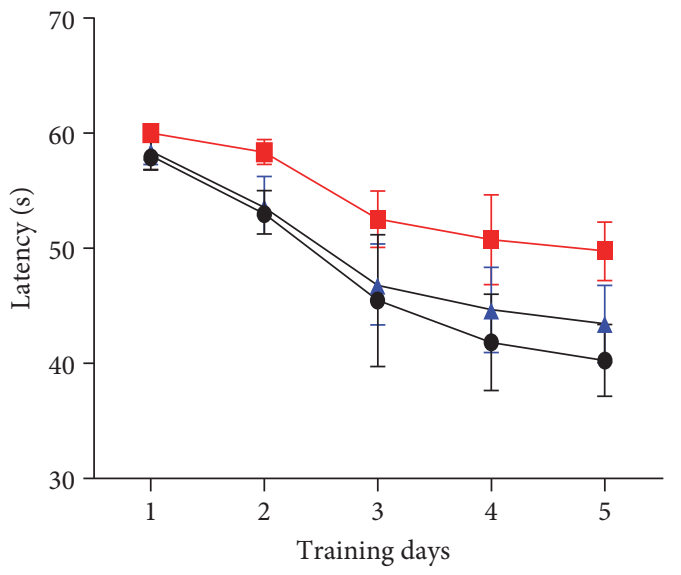

$$
\begin{array}{r}
\mathrm{Rg} 1 \\
- \\
-\mathrm{TT}
\end{array}
$$

(a)

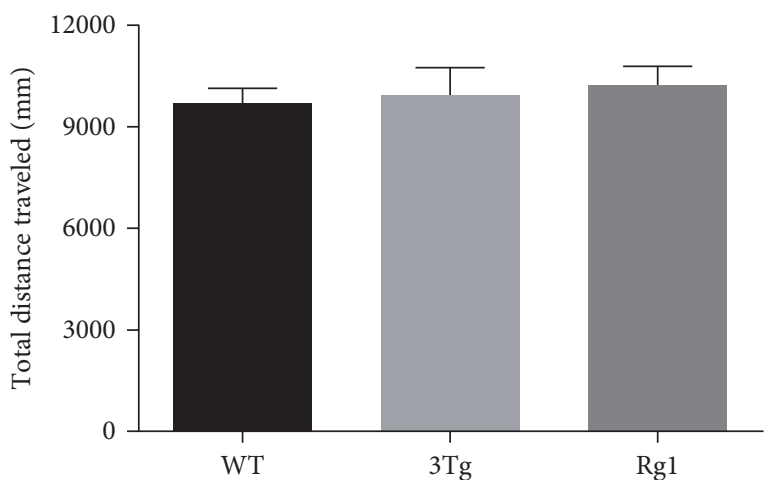

(b)

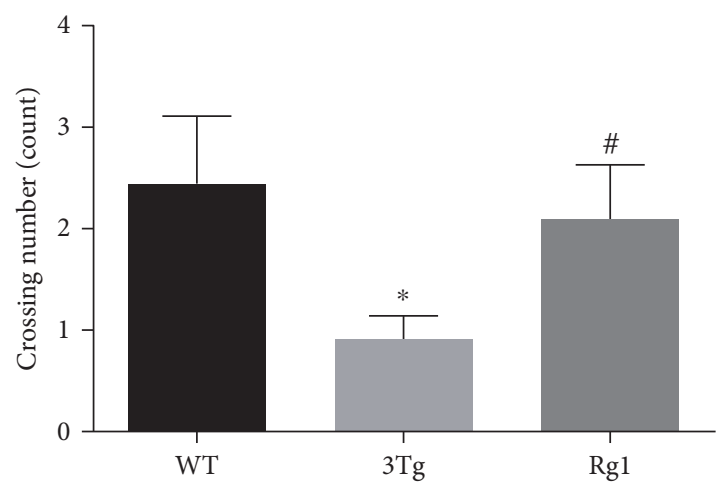

(d)

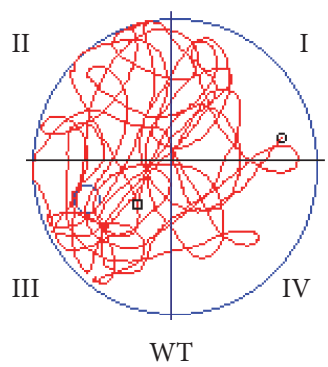

WT

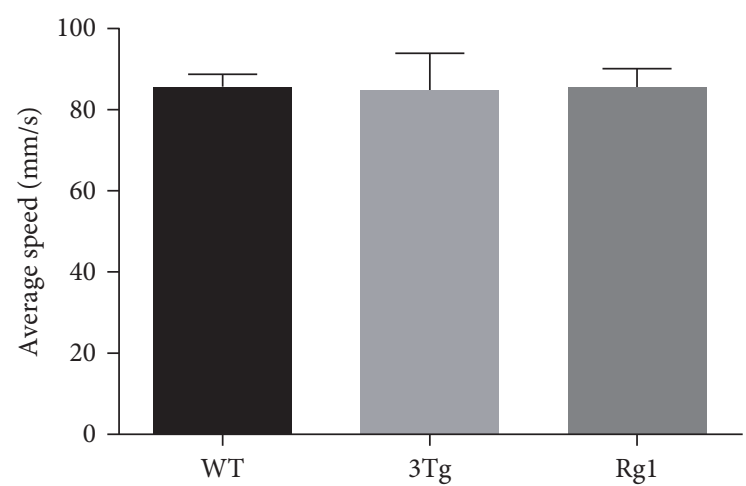

(c)

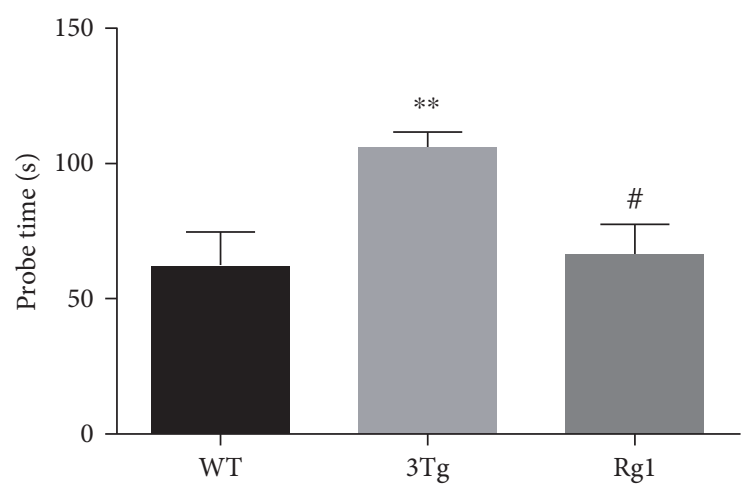

(e)

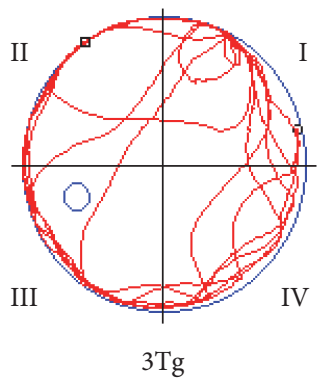

(f)

Figure 4: Continued. 


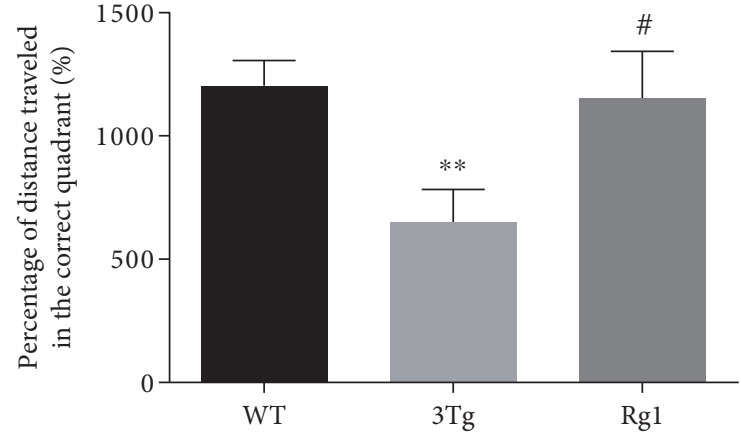

$(\mathrm{g})$

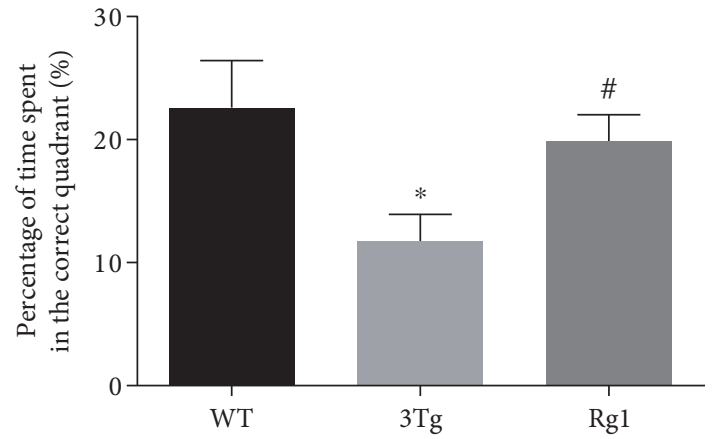

(h)

Figure 4: Memory behavior was measured by the Morris water maze. (a) Latency (s); (b) total distance traveled; (c) average speed; (d) crossing number; (e) probe time; (f) track diagram. (g) The percentage of distance traveled in the correct quadrant. (h) The percentage of time spent in the correct quadrant. The data were presented as mean \pm SEM. ${ }^{*} p<0.05$ and ${ }^{* *} p<0.01$ versus WT mice; ${ }^{\#} p<0.05$ versus $3 x T g-A D$ mice. $n=10-15$ for each group.

2.10. Gene Annotation. The Panther Bioinformatics Resource was used to carry out gene ontology annotation enrichment analysis. Panther analysis enabled the enrichment of biological process, molecular function, cellular components, and protein class (http://www.pantherdb.org/).

2.11. Western Blot Analysis. Hippocampal proteins from 3xTg-AD mice, 3xTg-AD-Rg1 mice, and WT mice were ultrasounded in $400 \mu \mathrm{L}$ lysis buffer (Beyotime, China) and $4 \mu \mathrm{L}$ protease and phosphatase inhibitor cocktail (Thermo Scientific, USA) on the ice, and then, the protein samples were centrifuged and collected. The protein concentration was measured with BCA protein assay kit (Thermo Scientific, USA). Each protein sample was added with loading buffer and heat for $7 \mathrm{~min}$ at 100 . Protein samples were separated on $10 \%$ PAGE gels with $5 \%$ stacking gels and transferred to PVDF membranes. The membrane was soaked in TBST buffer containing 5\% milk at room temperature for 2 hours. Subsequently, membranes were incubated with anti-SYN2 (rabbit polyclonal antibody, 1:3000), anti-SNP25 (rabbit polyclonal antibody, $1: 3000$ ), anti-complex 2 (rabbit polyclonal antibody, 1:3000), anti-PSD-95 (rabbit monoclonal antibody, 1:3000), and anti- $\beta$-actin (mouse monoclonal antibody, $1: 3000)$ in TBST buffer for $1.5 \mathrm{~h}$ at room temperature. After washing with TBST three times, the membrane was incubated with homologous secondary antibody (antirabbit or anti-mouse IgG HRPs) in TBST buffer for $60 \mathrm{~min}$. After repeatedly washing with TBST buffer, the membranes were developed using chemiluminescence reagents from an ECL kit (Pierce) and detected on a phosphorimager. The image of the membranes was analyzed by ImageQuant $1 \mathrm{D}$ software.

2.12. Statistical Analysis. Data were expressed as the mean \pm SD and analyzed by using SPSS 19.0 statistical software (SPSS Inc., Chicago, Illinois, USA). The different means among the groups were evaluated by one-way ANOVA. For all the one-way ANOVA, post hoc tests were performed using LSD test. The level of significance was set at $p<0.05$.

\section{Results}

3.1. Anti-Anxiety-Like Effects of Rg1 in $3 x T g-A D$ Mice. The anti-anxiety-like activity of $\operatorname{Rg} 1$ was assessed by the open field test and the elevated plus maze test. The open field test data were summarized in Figure 1. The data showed no significant differences in the total distance traveled among the three groups (Figure 1(a)), while the nontreated 3xTg-AD mice showed significantly decreased percentage of time $(p<0.05)$ and distance $(p<0.05)$ in the center compared with the WT mice (Figures 1(b) and 1(c)). Rg1-treated $3 \times \mathrm{Tg}-\mathrm{AD}$ mice showed an upward trend of the time spent and the distance traveled in the center compared with the nontreated 3xTg-AD mice (Figures 1(b) and 1(c)). The elevated plus maze test data are summarized in Figure 2. Compared with the WT mice, the percentage of time spent $(p<0.01$; Figure 2(a)) and the percentage of the distance traveled ( $p<0.05$; Figure 2(b)) in open arms, the number of entries into the open arms $(p<0.001$; Figure 2(c)), and the percentage of open arm entries $(p<0.001$; Figure $2(d))$ also were significantly decreased in the nontreated $3 \times \mathrm{Tg}-\mathrm{AD}$ mice. Increased trend of both the percentage of distance (Figure 2(b)) and the entry frequency (Figure 2(d)) in open arms was observed after the treatment with $\mathrm{Rg} 1$ in $3 \mathrm{xTg}$ $\mathrm{AD}$ mice. No differences were observed in the percentage of time in open arms (Figure 2(a)) and the number of entries into the open arms (Figure 2(c)) after the treatment with Rg1 in 3xTg-AD mice. These data suggested a mildly protective effect of $\operatorname{Rg} 1$ treatment against the anxiety-like behavior of 3xTg-AD mice.

3.2. Anti-Depression-Like Effects of Rg1 in 3xTg-AD Mice. The depression-like behaviors of the mice were assessed by the forced swimming test, as depicted in Figure 3. Compared with the WT mice, the 3xTg-AD mice had a longer duration of immobility $(p<0.05)$, while the duration of immobility was significantly decreased after the treatment of $\mathrm{Rg} 1$ $(p<0.05)$. These data indicated that Rg1 could significantly alleviate depression-like behavior of 3xTg-AD mice. 


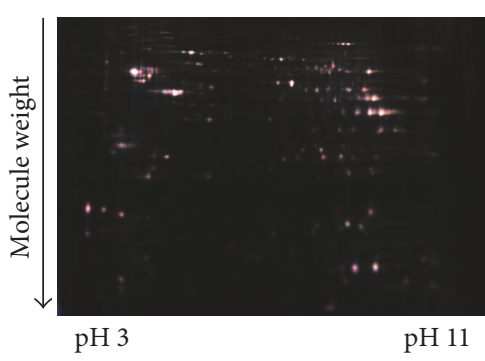

(a)

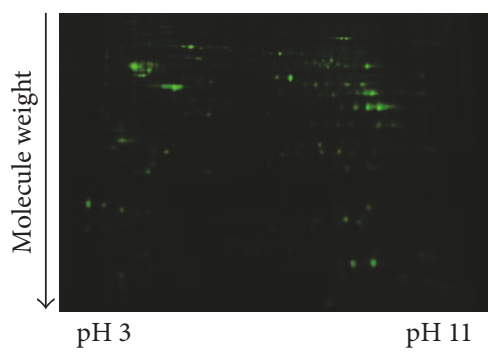

(c)

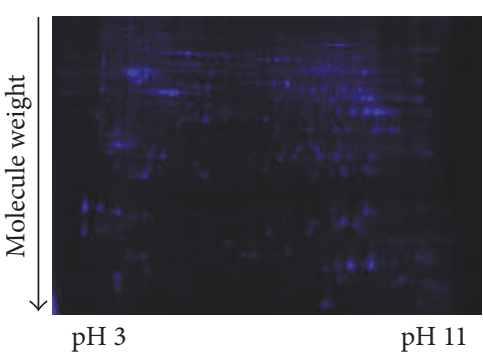

(b)

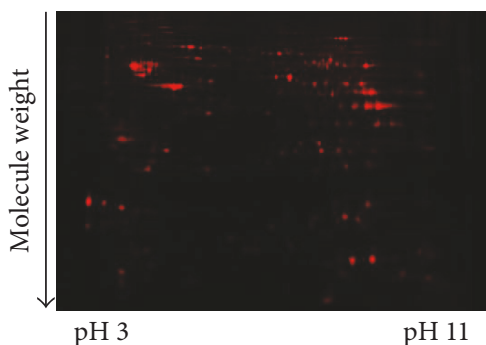

(d)

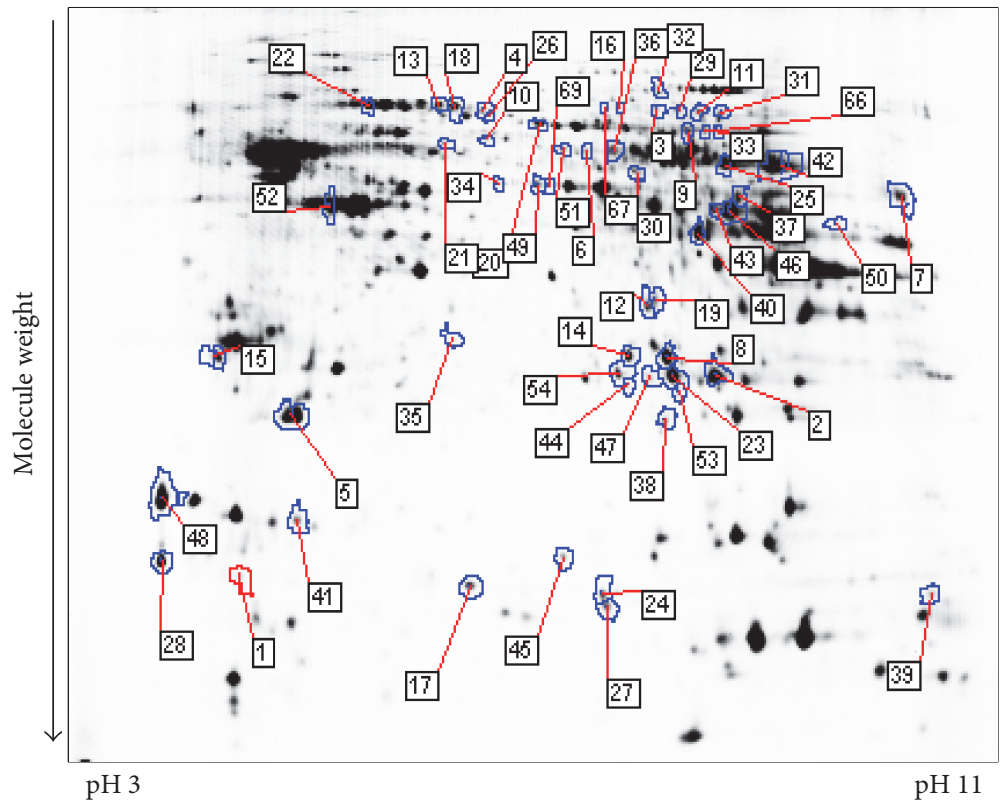

(e)

FIGURE 5: A representative 2D-DIGE gel image of hippocampal proteins from the WT mice and nontreated 3xTg-AD mice. Hippocampal proteins from the WT mice and nontreated 3xTg-AD mice were labeled with Cy3 or Cy5 dye, respectively ( $n=6$ for each group). An internal standard protein sample (a mixture of all hippocampus samples) was labeled with the Cy2 dye. The CyDye-labeled samples were combined, and the proteins were coseparated in the first dimension via IEF in $24 \mathrm{~cm} \mathrm{pH} \mathrm{3-11} \mathrm{nonlinear} \mathrm{IPG} \mathrm{strips,} \mathrm{followed} \mathrm{by} \mathrm{separation}$ in the second dimension via SDS-PAGE. Spots of interest were manually excised, digested, and subjected to identification by MALDITOF-MS/MS. (a) Cy2-labeled proteins as internal standards. (b) Cy3-labeled hippocampus proteins of WT mice. (c) Cy5-labeled hippocampus proteins of nontreated 3xTg-AD mice. (d) The merged image showing Cy2-, Cy3-, and Cy5-labeled proteins. (e) Greyscale 2D-DIGE gel image showing 47 differentially expressed protein spots identified by MALDI-TOF-MS/MS (black numbers with white square) in the hippocampus of nontreated 3xTg-AD mice compared with WT mice.

3.3. Improved Spatial Learning and Memory of 3xTg-AD Mice by Rg1 Treatment. The learning and memory ability of mice was measured by the Morris water maze test, as depicted in Figure 4. The total distance traveled (Figure 4(b)) and the average speed (Figure 4(c)) were not significantly different among the three groups, suggesting that the motor function of the experimental mice was not impaired. In the training period, the $3 \times \mathrm{Tg}-\mathrm{AD}$ mice spent longer time reaching the platform on the last four days compared to the WT mice (Figure 4(a)). Rg1-treated 3xTg-AD mice displayed reduced escape latency compared to the $3 \times \mathrm{T}$ - $\mathrm{AD}$ mice (Figure 4(a)). These data indicated that Rg1 treatment 


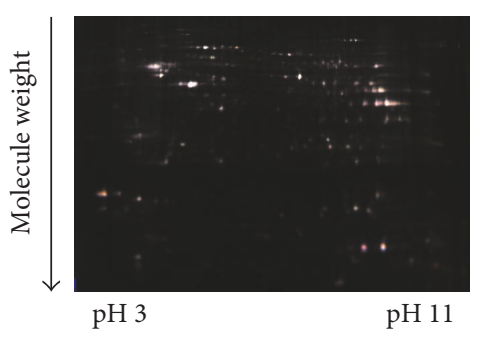

(a)

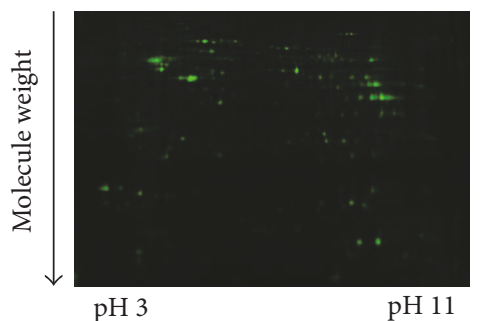

(c)

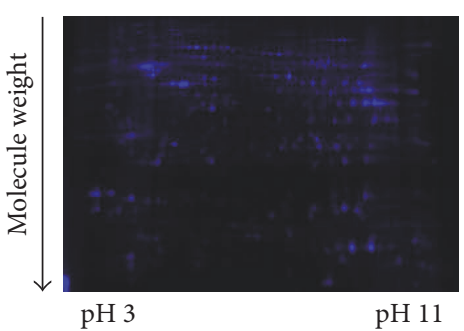

(b)

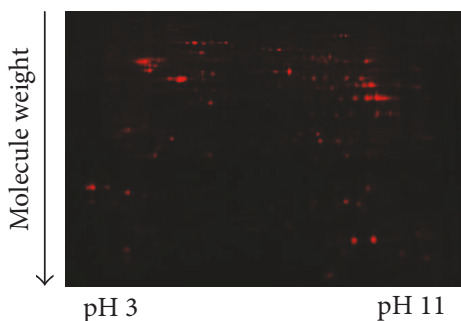

(d)

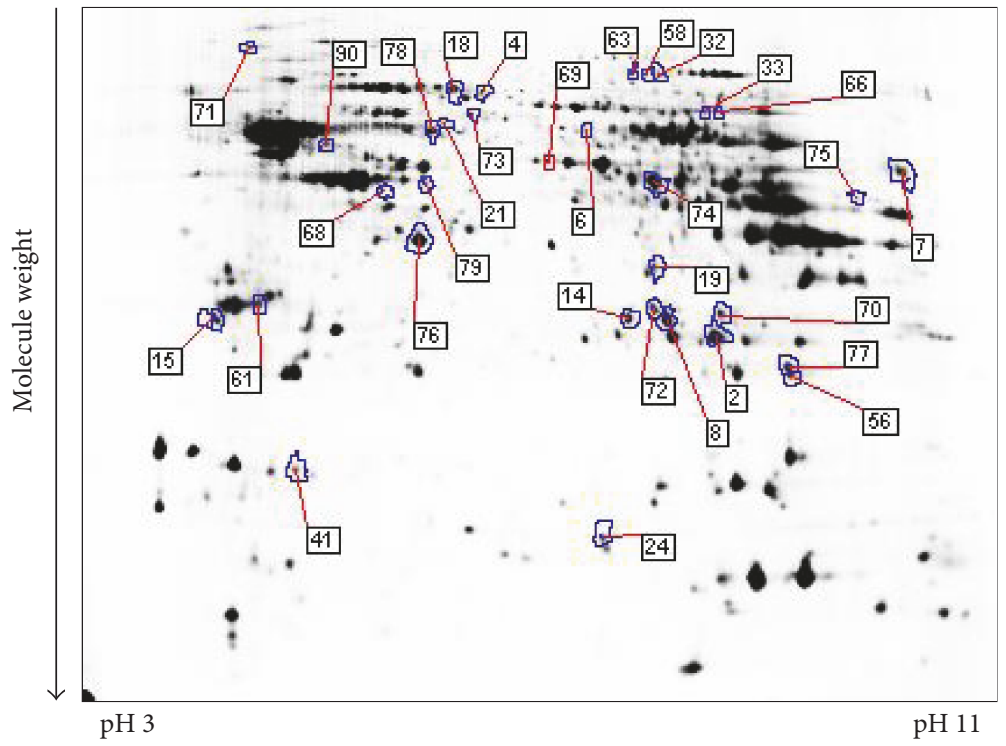

(e)

FIGURE 6: A representative 2D-DIGE gel image of hippocampal proteins from 3xTg-AD mice with or without Rg1 treatment. Hippocampal proteins from nontreated 3xTg-AD mice and Rg1-treated 3xTg-AD mice were labeled with Cy3 or Cy5 dye, respectively $(n=6$ for each group). An internal standard protein sample (a mixture of all hippocampus samples) was labeled with the Cy2 dye. The CyDye-labeled samples were combined, and the proteins were coseparated in the first dimension via IEF in $24 \mathrm{~cm} \mathrm{pH} 3-11$ nonlinear IPG strips, followed by separation in the second dimension via SDS-PAGE. Spots of interest were manually excised, digested, and subjected to identification by MALDI-TOF-MS/MS. (a) Cy2-labeled proteins as internal standards. (b) Cy3-labeled hippocampus proteins of nontreated 3xTg-AD mice. (c) Cy5-labeled hippocampus proteins of melatonin-treated 3xTg-AD mice. (d) The merged image showing Cy2-, Cy3-, and Cy5-labeled proteins. (e) Greyscale 2D-DIGE gel image showing 28 differentially expressed protein spots identified by MALDI-TOF-MS/MS (black numbers with white square) in the hippocampus of Rg1-treated 3xTg-AD mice compared with nontreated 3xTg-AD mice.

improved the learning ability of AD transgenic mice. In the probe period, the platform crossing number of $3 \times \mathrm{Tg}-\mathrm{AD}$ mice was significantly lower than the WT mice $(p<0.05$; Figure $4(\mathrm{~d})$ ), while the probe time of $3 \mathrm{xTg}-\mathrm{AD}$ mice was significantly higher than the WT mice $(p<0.01$; Figure $4(\mathrm{e}))$. The percentage of distance traveled $(p<0.01$; Figure $4(\mathrm{~g}))$ and the percentage of time spent $(p<0.05$; Figure $4(h))$ in the target quadrant of $3 \times \mathrm{Tg}-\mathrm{AD}$ mice were significantly decreased compared to the WT mice. Compared with the nontreated 3xTg-AD mice, the crossing number $(p<0.05$; Figure $4(d))$, the percentage of distance traveled $(p<0.05$; Figure $4(\mathrm{~g}))$, and the percentage of time spent $(p<0.05$; Figure $4(\mathrm{~h})$ ) in the target quadrant were significantly increased, and the probe time was significantly decreased in $3 x \mathrm{Tg}-\mathrm{AD}$ mice after the treatment of Rg1. The representative movement tracks of three groups were shown in Figure 4(f). These data demonstrated that Rg1 treatment could improve the spatial learning and memory ability of 3xTg-AD mice. 
TABLE 1: Differentially expressed hippocampus protein spots identified by 2D-DIGE/MALDI-TOF-MS/MS between the WT mice and nontreated 3xTg-AD mice.

\begin{tabular}{|c|c|c|c|c|c|c|}
\hline Spot number ${ }^{\mathrm{a}}$ & Accession number & Protein name ${ }^{b}$ & $\operatorname{MW}(\mathrm{Da})^{\mathrm{c}}$ & Mascot score & $\begin{array}{l}3 \mathrm{Tg} \text { ver } \\
p \text { value }\end{array}$ & $\begin{array}{r}\text { sus WT } \\
\text { Ratio }\end{array}$ \\
\hline \multicolumn{7}{|c|}{ Modulation of synaptic transmission } \\
\hline 5 & PEBP1_MOUSE & Phosphatidylethanolamine-binding protein 1 & 20988 & 198 & 0.0018 & 1.11 \\
\hline 15 & SNP25_MOUSE & Synaptosomal-associated protein 25 & 23528 & 393 & 0.0074 & -1.22 \\
\hline 29 & SYN2_MOUSE & Synapsin-2 & 63618 & 128 & 0.023 & -1.19 \\
\hline 41 & CPLX2_MOUSE & Complexin-2 & 15499 & 112 & 0.034 & -1.5 \\
\hline \multicolumn{7}{|c|}{ Glycolytic process } \\
\hline 2 & TPIS_MOUSE & Triosephosphate isomerase & 32684 & 377 & 0.00026 & -1.38 \\
\hline 8 & PGAM1_MOUSE & Phosphoglycerate mutase 1 & 28928 & 546 & 0.0033 & -1.23 \\
\hline 33 & KPYM_MOUSE & Pyruvate kinase isozymes M1/M2 & 58378 & 52 & 0.027 & 1.47 \\
\hline 34 & ENOA_MOUSE & Alpha-enolase & 47453 & 349 & 0.028 & 1.21 \\
\hline 40 & ALDOC_MOUSE & Fructose-bisphosphate aldolase C & 39769 & 350 & 0.033 & -1.08 \\
\hline 49 & ENOB_MOUSE & Beta-enolase & 47337 & 256 & 0.048 & 1.21 \\
\hline 50 & PGK1_MOUSE & Phosphoglycerate kinase 1 & 44921 & 134 & 0.048 & 1.27 \\
\hline \multicolumn{7}{|c|}{ Response to stress } \\
\hline 1 & PEA15_MOUSE & Astrocytic phosphoprotein PEA-15 & 15102 & 53 & 0.00024 & 1.35 \\
\hline 10 & PDIA3_MOUSE & Protein disulfide-isomerase A3 & 57099 & 241 & 0.0045 & 1.17 \\
\hline 18 & ALBU_MOUSE & Serum albumin & 70700 & 676 & 0.0086 & 1.24 \\
\hline 19 & VDAC1_MOUSE & Voltage-dependent anion-selective channel protein 1 & 32502 & 99 & 0.0089 & 1.11 \\
\hline 32 & TRFE_MOUSE & Serotransferrin & 78841 & 149 & 0.027 & 1.28 \\
\hline 45 & SODC_MOUSE & Superoxide dismutase $[\mathrm{Cu}-\mathrm{Zn}]$ & 16104 & 298 & 0.037 & 1.11 \\
\hline 52 & ACTB_MOUSE & Actin, cytoplasmic 1 & 42052 & 362 & 0.049 & -1.11 \\
\hline 90 & ANXA7_MOUSE & Annexin A7 & 50178 & 150 & 0.049 & 1.14 \\
\hline \multicolumn{7}{|c|}{ Negative regulation of apoptotic process } \\
\hline 12 & VDAC2_MOUSE & Voltage-dependent anion-selective channel protein 2 & 32340 & 169 & 0.0052 & 1.11 \\
\hline 43 & KCRU_MOUSE & Creatine kinase U-type, mitochondrial & 47373 & 207 & 0.036 & -1.2 \\
\hline 51 & COR1A_MOUSE & Coronin $-1 \mathrm{~A}$ & 51641 & 88 & 0.049 & -1.08 \\
\hline \multicolumn{7}{|l|}{ Others } \\
\hline 3 & HBA_MOUSE & Hemoglobin subunit alpha & 15133 & 60 & 0.0014 & -1.26 \\
\hline 4 & DPYL2_MOUSE & Dihydropyrimidinase-related protein 2 & 62638 & 441 & 0.0016 & -1.4 \\
\hline 6 & SERA_MOUSE & D-3-Phosphoglycerate dehydrogenase & 57347 & 115 & 0.002 & -1.33 \\
\hline 7 & EF1A1_MOUSE & Elongation factor 1-alpha 1 & 50424 & 124 & 0.0021 & 1.28 \\
\hline 9 & DPYL5_MOUSE & Dihydropyrimidinase-related protein 5 & 62047 & 141 & 0.0039 & 1.23 \\
\hline 11 & TKT_MOUSE & Transketolase OS = Mus musculus & 68272 & 92 & 0.0048 & -1.22 \\
\hline 13 & GRP75_MOUSE & Stress-70 protein, mitochondrial & 73701 & 244 & 0.0067 & -1.29 \\
\hline 16 & WDR1_MOUSE & WD repeat-containing protein 1 & 67049 & 339 & 0.0078 & -1.4 \\
\hline 17 & NEUG_MOUSE & Neurogranin & 7720 & 66 & 0.0082 & 1.27 \\
\hline 21 & VATB2_MOUSE & V-type proton ATPase subunit B, brain isoform & 56857 & 337 & 0.011 & 1.55 \\
\hline 22 & HSP7C_MOUSE & Heat shock cognate $71 \mathrm{kDa}$ protein & 71055 & 408 & 0.012 & -1.14 \\
\hline 24 & B0R1E3_MOUSE & Histidine triad nucleotide-binding protein 1 & 13601 & 144 & 0.013 & 1.81 \\
\hline 25 & ATPA_MOUSE & ATP synthase subunit alpha, mitochondrial & 59830 & 279 & 0.015 & -1.14 \\
\hline 27 & HINT1_MOUSE & Histidine triad nucleotide-binding protein 1 & 13882 & 108 & 0.021 & 1.21 \\
\hline 28 & ATPD_MOUSE & ATP synthase subunit delta, mitochondrial & 17589 & 485 & 0.022 & 1.37 \\
\hline 30 & SEP11_MOUSE & Septin-11 & 50005 & 66 & 0.023 & 1.1 \\
\hline 35 & PA1B2_MOUSE & Platelet-activating factor acetylhydrolase IB subunit beta & 25736 & 61 & 0.028 & 1.15 \\
\hline 36 & TBA1A_MOUSE & Tubulin alpha-1A chain & 50788 & 103 & 0.029 & -1.2 \\
\hline 37 & FUMH_MOUSE & Fumarate hydratase, mitochondrial & 54550 & 66 & 0.031 & -1.14 \\
\hline 39 & ACO13_MOUSE & Acyl-coenzyme A thioesterase 13 & 15287 & 97 & 0.031 & 1.11 \\
\hline
\end{tabular}


TABLE 1: Continued.

\begin{tabular}{|c|c|c|c|c|c|c|}
\hline Spot number ${ }^{\mathrm{a}}$ & Accession number & Protein name ${ }^{\mathrm{b}}$ & $\mathrm{MW}(\mathrm{Da})^{\mathrm{c}}$ & Mascot score & $\begin{array}{l}3 \text { Tg ver } \\
p \text { value }\end{array}$ & $\begin{array}{l}\text { us WT } \\
\text { Ratio }^{\text {d }}\end{array}$ \\
\hline 44 & F2Z471_MOUSE & Voltage-dependent anion-selective channel protein 1 & 28254 & 216 & 0.036 & 1.16 \\
\hline 47 & GT2D1_MOUSE & $\begin{array}{c}\text { General transcription factor II-I repeat } \\
\text { domain-containing protein } 1\end{array}$ & 124546 & 35 & 0.046 & 1.14 \\
\hline 48 & CALM_MOUSE & Calmodulin & 16827 & 338 & 0.046 & 1.33 \\
\hline 53 & PSA2_MOUSE & Proteasome subunit alpha type- 2 & 26024 & 190 & 0.049 & 1.19 \\
\hline 67 & DHSA_MOUSE & $\begin{array}{l}\text { Succinate dehydrogenase [ubiquinone] } \\
\text { flavoprotein subunit, mitochondrial }\end{array}$ & 73623 & 192 & 0.025 & -1.33 \\
\hline
\end{tabular}

${ }^{\mathrm{a}}$ Protein ID assigned manually. ${ }^{\mathrm{b}}$ Protein name identified by MALDI-TOF-MS/MS. ${ }^{\mathrm{c}}$ Theoretical molecular weight of the proteins. ${ }^{\mathrm{d}}$ The ratio in spot intensity from $3 \mathrm{xTg}$-AD mice compared to WT mice. $N=6$ for each group.

\subsection{Differentially Expressed Hippocampal Proteins among} the WT Mice, Nontreated 3xTg-AD Mice, and Rg1-Treated $3 x \operatorname{Tg}$-AD Mice. To identify the potential molecules involved in the neuroprotection of Rg1, comparative proteomic analysis was performed on the hippocampal samples from the WT mice and $3 \times \mathrm{Tg}-\mathrm{AD}$ mice with or without $\mathrm{Rg} 1$ treatment. Representative 2D-DIGE gel images of hippocampal proteins isolated from the three groups of mice were shown in Figures 5(a), 5(b), 5(c), and 5(d) and Figures 6(a), 6(b), $6(\mathrm{c})$, and 6(d). Spots with a fold change of 1.2 or greater and a $p$ value $\leq 0.05$ were recommended as differentially expressed protein spots. A total of 75 differentially expressed protein spots were annotated in the form of protein ID and identified with MS (Figures 5(e) and 6(e)). The mascot scores, protein names, theoretical molecular weight, $p$ values, and fold-change levels of these differentially expressed proteins were displayed in Tables 1 and 2.

3.5. Identification of Differentially Expressed Hippocampal Proteins between WT and 3xTg-AD Mice. As depicted in Table 1, a total of 47 differentially expressed proteins were identified with MS between 3xTg-AD mice and the WT mice. These differentially expressed proteins were highly correlated with synaptic transmission, glycolytic process, response to stress, and negative regulation of apoptotic process. 10.6\% of the differentially expressed proteins was related to synaptic transmission and $14.9 \%$ of the proteins was involved in glycolytic process. $17 \%$ of the proteins was involved in response to stress, and $6.4 \%$ of the proteins participated in the regulation of apoptotic process. Among these proteins, a total of 27 proteins, including memory-related proteins such as synaptosomal-associated protein 25 (SNP25), synapsin-2 (SYN2), and complexin-2 (CPLX2), in 3xTg-AD mice compared with WT mice were significantly downregulated, while a total of 20 proteins were significantly upregulated.

3.6. The Effect of Rg1 Treatment on the Protein Expression in Hippocampus of 3xTg-AD Mice. As depicted in Table 2, a total of 28 differentially expressed proteins were identified with MS between Rg1-treated 3xTg-AD mice and nontreated $3 x T g-A D$ mice. Among these differentially expressed proteins, $14.3 \%$ of the proteins was related to synaptic transmission and $10.7 \%$ of the proteins was involved in glycolytic process. $21.4 \%$ of the proteins was involved in response to stress, and $10.7 \%$ of the proteins participated in the regulation of apoptotic process. A total of 16 proteins were downregulated in 3xTg-AD mice after the treatment of Rg1, and a total of 12 proteins were upregulated. Furthermore, we found that Rg1 treatment was able to modulate the expression of multiple synaptic proteins such as SNP25 and CPLX2.

3.7. Enrichment Analysis of the Differentially Expressed Protein. To investigate the biological function of the identified hippocampal proteins, we carried out Gene Ontology (GO) annotation search using the Mus musculus databases (http://www.pantherdb.org/). GO annotations were available for the 75 identified proteins included repeats, and the 61 proteins were grouped according to their molecular function, biological processes, cellular component, and protein class (Figures 7(a), 7(b), 7(c), and 7(d)). Molecular functions of the identified proteins mainly involved catalytic activity (45.1\%), binding (27.5\%), transporter activity $(9.8 \%)$, and structural molecule activity $(9.8 \%)$. Biological process of the identified proteins mainly involved cellular process (31.2\%), metabolic process $(23.4 \%)$, cellular component organization or biogenesis (11.7\%), and localization (10.4\%). Cellular component of the identified proteins included cellular part (53.1\%), organelles $(25 \%)$, and macromolecular complex (15.6\%). Protein class of the identified proteins mainly involved cytoskeletal protein (17.3\%), hydrolase (17.3\%), and lyase $(9.6 \%)$.

3.8. Validation of Differentially Expressed Proteins by Western Blot Analysis. To confirm the data obtained by 2DDIGE, Western blot analysis was performed. Three synaptic proteins, CPLX2, SYN2, and SNP25, were selected for further validation. As depicted in Figure 8, in accordance with the results from 2D-DIGE, the expression of CPLX2, SYN2, and SNP25 was significantly downregulated in 3xTg-AD mice relative to the WT mice, while the expression of these proteins was modulated by the treatment of Rg1. Besides, we also determine the expression of PSD-95 in the hippocampus of $3 \times \mathrm{Tg}-\mathrm{AD}$ mice. The data showed that the expression of PSD-95 was significantly decreased in $3 \times \mathrm{Tg}$-AD mice compared with the WT mice $(p<0.05)$, while the expression of this protein was significantly increased after the treatment of $\operatorname{Rg} 1(p<0.01)$. 
TABLE 2: Differentially expressed hippocampus protein spots identified by 2D-DIGE/MALDI-TOF-MS/MS between 3xTg-AD mice treated with and without $\operatorname{Rg} 1$.

\begin{tabular}{|c|c|c|c|c|c|c|}
\hline \multirow[t]{2}{*}{ Spot number ${ }^{\mathrm{a}}$} & \multirow[t]{2}{*}{ Accession number } & \multirow[t]{2}{*}{ Protein name ${ }^{b}$} & \multirow[t]{2}{*}{$\mathrm{MW}(\mathrm{Da})^{\mathrm{c}}$} & \multirow[t]{2}{*}{ Mascot score } & \multicolumn{2}{|c|}{$\begin{array}{c}\text { Rg1-3Tg versus } \\
\text { 3Tg }\end{array}$} \\
\hline & & & & & $p$ value & Ratio $^{\mathrm{d}}$ \\
\hline \multicolumn{7}{|c|}{ Modulation of synaptic transmission } \\
\hline 15 & SNP25_MOUSE & Synaptosomal-associated protein 25 & 23528 & 393 & 0.045 & 1.17 \\
\hline 41 & CPLX2_MOUSE & Complexin-2 & 15499 & 112 & 0.0016 & 1.66 \\
\hline 58 & SYN1_MOUSE & Synapsin-1 & 74223 & 96 & 0.012 & -1.39 \\
\hline 63 & NSF-MOUSE & Vesicle-fusing ATPase & 83131 & 63 & 0.019 & -1.26 \\
\hline \multicolumn{7}{|c|}{ Glycolytic process } \\
\hline 14 & PGAM1_MOUSE & Phosphoglycerate mutase 1 & 28928 & 623 & 0.0067 & 1.32 \\
\hline 33 & KPYM_MOUSE & Pyruvate kinase isozymes M1/M2 & 58378 & 52 & 0.036 & -1.12 \\
\hline 69 & ENOA_MOUSE & Alpha-enolase & 47453 & 136 & 0.0092 & -1.12 \\
\hline \multicolumn{7}{|c|}{ Response to stress } \\
\hline 19 & VDAC1_MOUSE & Voltage-dependent anion-selective channel protein 1 & 32502 & 99 & 0.047 & -1.08 \\
\hline 32 & TRFE_MOUSE & Serotransferrin & 78841 & 149 & 0.0021 & -1.39 \\
\hline 61 & 1433Z_MOUSE & 14-3-3 protein zeta/delta & 27925 & 151 & 0.01 & 1.19 \\
\hline 72 & CAH2_MOUSE & Carbonic anhydrase 2 & 29129 & 195 & 0.018 & 1.14 \\
\hline 74 & GLNA_MOUSE & Glutamine synthetase & 42834 & 412 & 0.023 & 1.09 \\
\hline 90 & ANXA7_MOUSE & Annexin A7 & 50178 & 150 & 0.0072 & -1.22 \\
\hline \multicolumn{7}{|c|}{ Negative regulation of apoptotic process } \\
\hline 2 & TPIS_MOUSE & Triosephosphate isomerase & 32684 & 377 & $6.60 E-06$ & 1.31 \\
\hline 18 & ALBU_MOUSE & Serum albumin & 70700 & 676 & 0.023 & -1.24 \\
\hline 77 & GSTP1_MOUSE & Glutathione S-transferase P 1 & 23765 & 434 & 0.04 & 1.14 \\
\hline \multicolumn{7}{|l|}{ Others } \\
\hline 4 & DPYL2_MOUSE & Dihydropyrimidinase-related protein 2 & 62638 & 441 & 0.031 & 1.29 \\
\hline 6 & SERA_MOUSE & D-3-Phosphoglycerate dehydrogenase & 57347 & 115 & 0.016 & 1.21 \\
\hline 7 & EF1A1_MOUSE & Elongation factor 1-alpha 1 & 50424 & 124 & 0.043 & -1.16 \\
\hline 24 & B0R1E3_MOUSE & Histidine triad nucleotide-binding protein 1 & 13601 & 144 & 0.003 & -1.74 \\
\hline 56 & B1AXW5_MOUSE & Peroxiredoxin-1 (fragment) & 19086 & 379 & 0.00015 & 1.21 \\
\hline 68 & TMOD2_MOUSE & Tropomodulin-2 & 39487 & 81 & 0.0052 & 1.1 \\
\hline 70 & DHPR_MOUSE & Dihydropteridine reductase & 25782 & 360 & 0.0094 & 1.1 \\
\hline 73 & E0CZA1_MOUSE & T-complex protein 1 subunit epsilon (fragment) & 21569 & 49 & 0.019 & -1.32 \\
\hline 75 & G5E8R0_MOUSE & Tropomyosin 1, alpha, isoform CRA_i & 28383 & 275 & 0.034 & 1.15 \\
\hline 76 & GBB2_MOUSE & $\begin{array}{l}\text { Guanine nucleotide-binding protein } \\
\mathrm{G}(\mathrm{I}) / \mathrm{G}(\mathrm{S}) / \mathrm{G}(\mathrm{T}) \text { subunit beta-2 }\end{array}$ & 38048 & 428 & 0.039 & 1.05 \\
\hline 78 & VATB2_MOUSE & V-type proton ATPase subunit B, brain isoform & 56857 & 350 & 0.042 & -1.93 \\
\hline 79 & ACTG_MOUSE & Actin, cytoplasmic 2 & 42108 & 176 & 0.049 & 1.08 \\
\hline
\end{tabular}

${ }^{a}$ Protein ID assigned manually. ${ }^{b}$ Protein name identified by MALDI-TOF-MS/MS. ${ }^{\circ}$ Theoretical molecular weight of the protein(s). ${ }^{\mathrm{d}}$ The ratio in spot intensity from Rg1-treated 3xTg-AD mice compared to nontreated 3xTg-AD mice. $N=6$ for each group.

\section{Discussion}

In the present study, we first employed a proteomic approach to investigate the protective effects of Rg1 in 3xTg-AD mice. The 3xTg-AD mice exhibited neurodegenerative changes associated with $\mathrm{A} \beta$ and tau deposition that were similar to those observed in patients with $\mathrm{AD}$ [28]. Thus, the 3xTgAD mouse model is a reliable animal model for studies of $\mathrm{AD}$ prevention and treatment. Besides, 3xTg-AD mice also displayed obviously synaptic deficit upregulating ryanodine receptor activity which was associated with the symptoms of depression [29]. Overall, 3xTg-AD mice could show the symptom of memory deficit and depression-like behavior.

Additionally, several studies have shown that Rg1 could inhibit morphine-induced spatial memory deficit in both freely moving and anaesthetized rats [30] and produced antidepressant effects via activation of the BDNF signaling pathway upregulating neurogenesis in the hippocampus of mice [31]. Importantly, BDNF, a neurotrophin, plays important roles in protecting and regulating the structure and function of neurons throughout life [32]. Recent studies reported that ginsenoside $\operatorname{Rg} 1$ ameliorated hippocampal long-term 


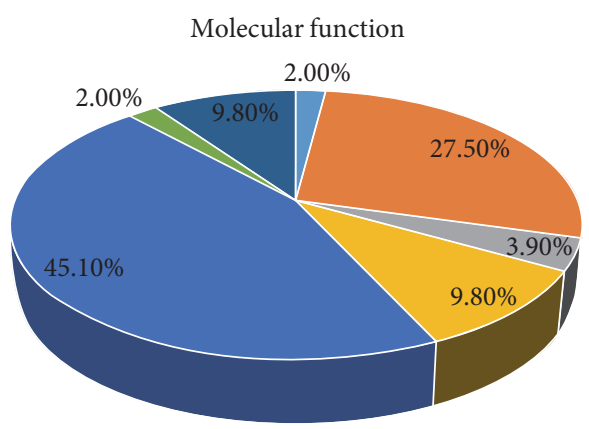

- Translation regulator activity

- Receptor activity

- Catalytic activity

- Transporter activity

- Binding

- Structural molecule activity

- Antioxidant activity

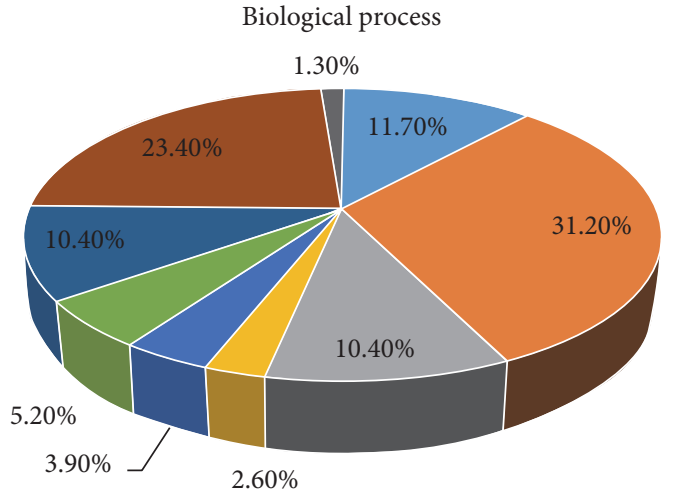

- Cellular component organization or biogenesis

- Cellular process

- Localization

- Biological regulation

- Response to stimulus

- Developmental process

- Multicellular organismal process

- Metabolic process

- Immune system process

(b)

Protein class

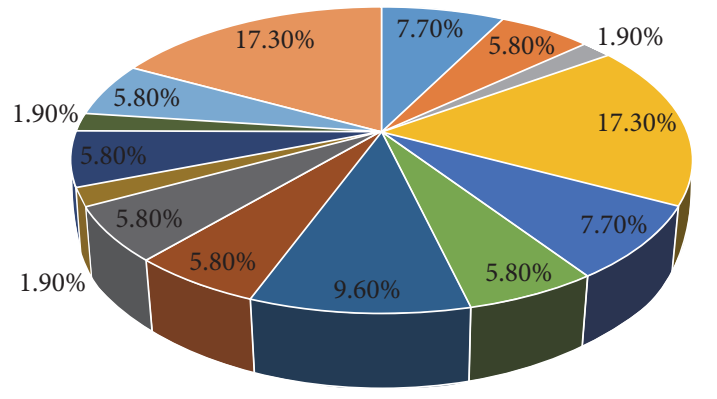

- Transporter

- Hydrolase

- Lyase

- Transcription factor

- Calcium-binding protein

- Membrane traffic protein

- Oxidoreductase
- Transfer/carrier protein

- Nucleic acid binding

- Cytoskeletal protein

- Chaperone

- Enzyme modulator

Transferase

- Ligase

(c)

FIGURE 7: PANTHER functional enrichment analysis of differentially expressed proteins. (a) Enrichment analysis by molecular function. (b) Enrichment analysis by biological process. (c) Enrichment analysis by cellular component. (d) Enrichment analysis by protein class.

potentiation and promoted memory $[33,34]$. Moreover, Shi et al. also found that Rg1 improved the spatial learning and memory via promoting nonamyloidgenic cleavage of APP, which activated estrogen receptor signaling to MAPK/ERK and PI3K/Akt [35]. Besides, Yang et al. found that longterm Rg1 supplementation improved age-related cognitive decline by promoting synaptic plasticity-associated protein expression, including synaptophysin, N-methyl-D-aspartate receptor subunit 1, postsynaptic density-95, and calcium/calmodulin-dependent protein kinase II alpha [36]. Consistently, we also found that Rg1 upregulated the expression of synaptic proteins such as SYN1, PSD-95, and SNP25 in the hippocampus of 3xTg-AD mice. Therefore, our data demonstrated that the memory impairment and depression-like behavior were ameliorated by the treatment of Rg1, suggesting the protective effects of $\operatorname{Rg} 1$ against $\mathrm{AD}$. In addition, we 


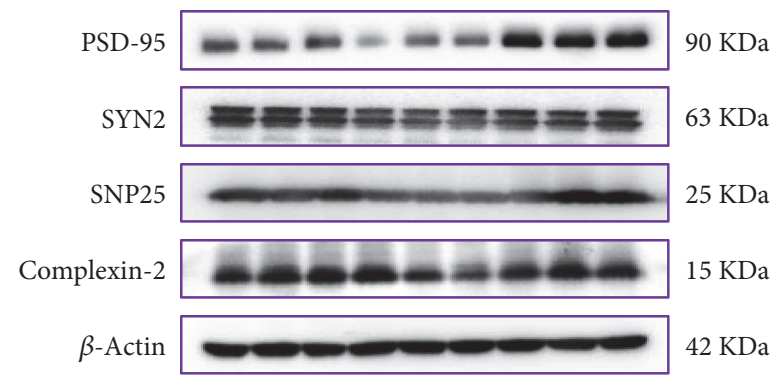

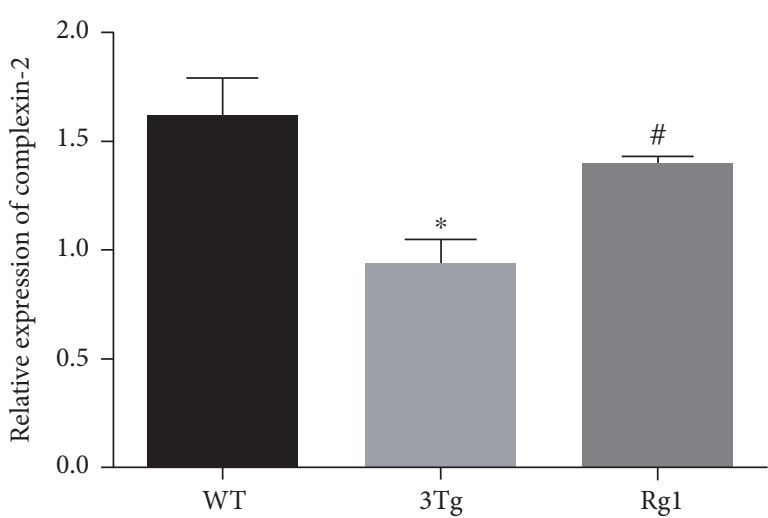

(b)

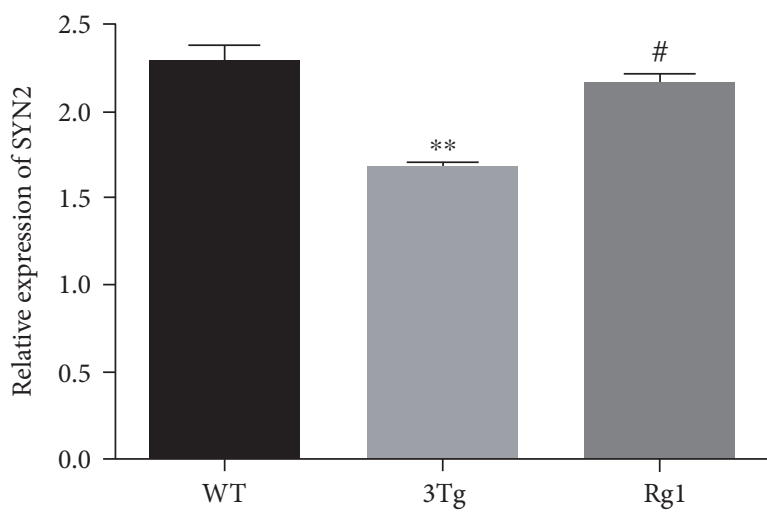

(d)

(a)

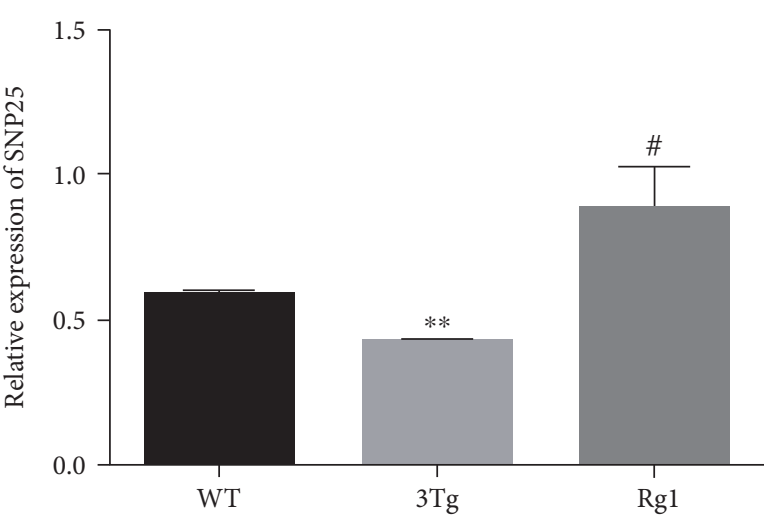

(c)

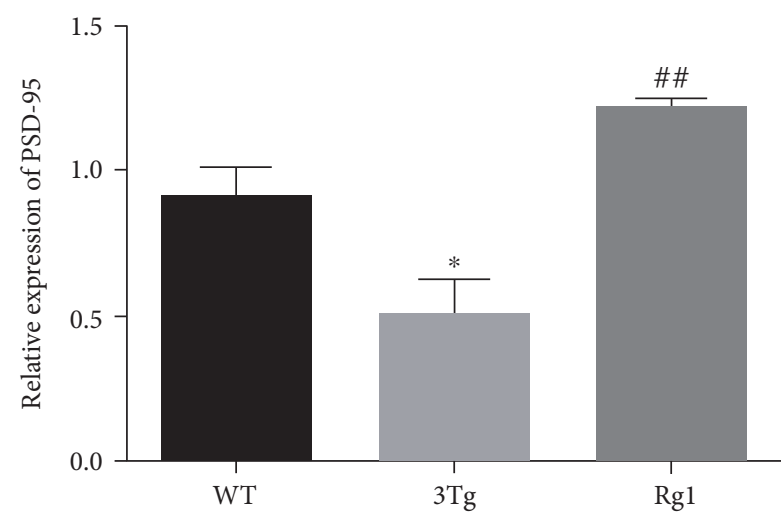

(e)

Figure 8: Validation of differentially expressed proteins of CPLX2, SNP25, and SYN2 by Western blot analysis. (a and b) The relative levels of CPLX2 in the hippocampus in WT mice, nontreated 3xTg-AD mice, and Rg1-treated 3xTg-AD mice. (a and c) The relative levels of SNP25 in the hippocampus in WT mice, nontreated 3xTg-AD mice, and Rg1-treated 3xTg-AD mice. (a and d) The relative levels of SYN2 in the hippocampus in WT mice, nontreated 3xTg-AD mice, and Rg1-treated 3xTg-AD mice. ( $\mathrm{a}$ and e) The relative levels of PSD-95 in the hippocampus in WT mice, nontreated 3xTg-AD mice, and Rg1-treated 3xTg-AD mice. The data were presented as mean \pm SEM. ${ }^{*} p<0.05$ and ${ }^{* *} p<0.01$ versus WT; ${ }^{*} p<0.05$ and ${ }^{\# \#} p<0.01$ versus 3 Tg. $n=3$ for each group.

successfully identified 28 proteins in the hippocampus that were differentially expressed in $3 \mathrm{xTg}$-AD mice with or without $\operatorname{Rg} 1$ treatment by proteomic analysis.

The behavioral tests, that is, the open field test, the elevated plus maze test, the tail suspension test, and the Morris water maze test, were used to evaluate the anxiety and depression-like behaviors and memory impairment in 3xTg-AD mice. Namely, the open field test and the elevated plus maze were used to explore the anxiety behavior in $3 \mathrm{xTg}$-AD mice, the tail suspension test was used to explore the depression-like behavior in 3xTg-AD mice, and Morris water maze test was used to determine the memory impairment in 3xTg-AD mice. Our data demonstrated that Rg1 treatment could improve depression-like behavior and memory impairment of the 3xTg-AD mice, but its effect on anxiety-like behavior was not obvious, which were consistent with the previous data showing that $\operatorname{Rg} 1$ treatment did not produce significant effects on anxiety-like behavior in APP/ V7171 transgenic mice bearing the "London" mutant of APP $[37,38]$, which displayed obvious cognitive impairment and neuroinflammation associated with pathological features of AD. Furthermore, Rg1 was shown to repair hippocampal long-term potentiation (LTP) and improved memory impairment in APP/PS1 mice, likely through facilitating 


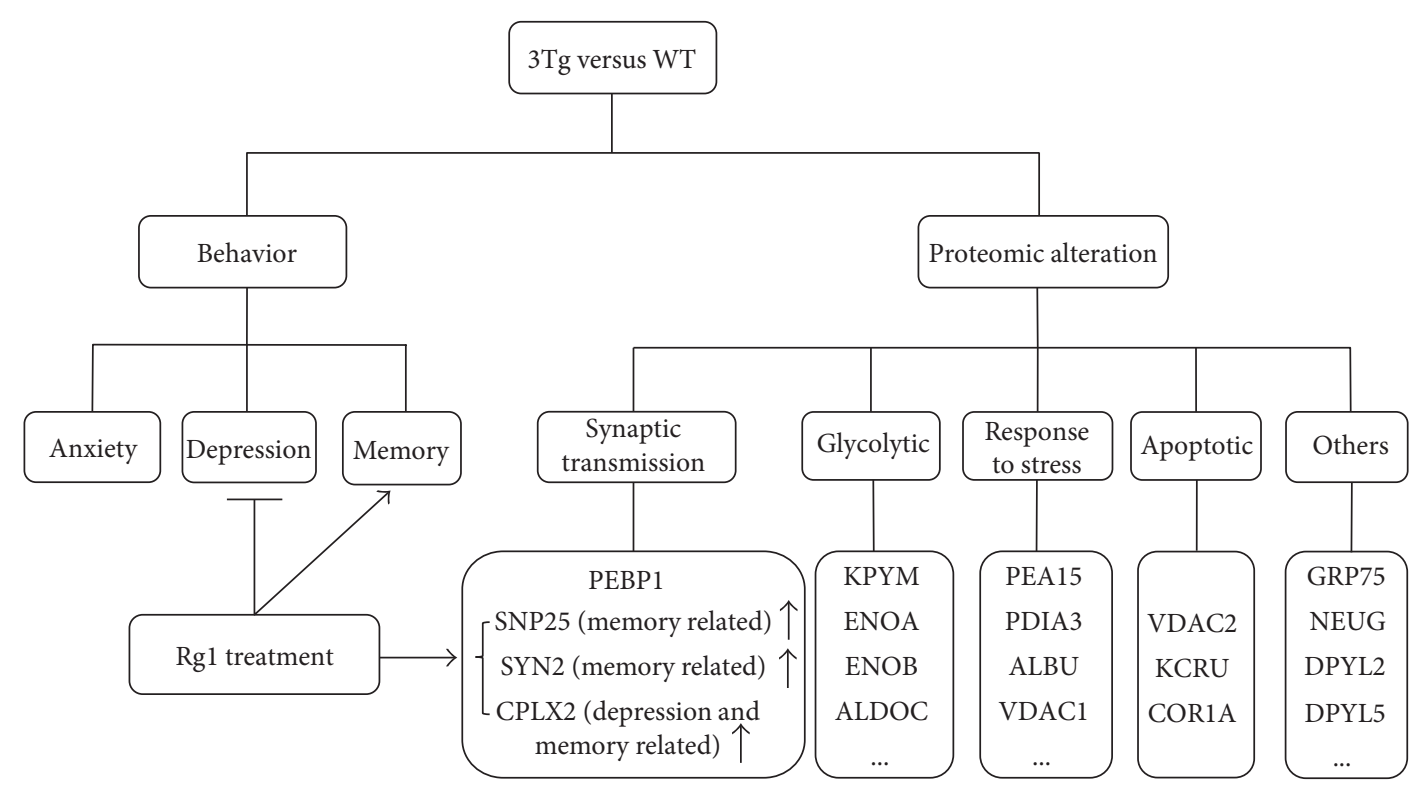

FIGURE 9: Schematic diagram demonstrating the effects of Rg1 treatment on behavior and hippocampal proteome. On the one hand, Rg1 treatment could improve the memory impairment and ameliorate the depression-like behaviors of 3xTg-AD mice. On the other hand, proteomic analysis revealed that Rg1 could modulate the expression of multiple hippocampal proteins in $3 \times \mathrm{Tg}$-AD mice. Notably, complexin-2 (CPLX2), a depression- and memory-related protein, and synapsin-2 (SYN2) and synaptosomal-associated protein 25 (SNP25), two memory-related proteins, were significantly downregulated in the hippocampus of 3xTg-AD mice compared with the WT mice, and the treatment of Rg1 modulated the expression of CPLX2 and SNP25 in hippocampus of 3xTg-AD mice.

the clearance of $\mathrm{AD}$-associated proteins and activating the BDNF-TrkB pathway [39]. In addition, Rg1 exhibited antidepressant-like effects in multiple depression-like models $[40,41]$. These data collectively demonstrated that Rg1 exerted the neuroprotective effects against memory impairment and depression-like behavior in AD.

Here, the 2D-DIGE technology by using a mixed sample internal standard was applied to identify proteins with distinct molecular functions which could provide a better insight into the underlying molecular mechanisms involved in the neuroprotection of $\mathrm{AD}$ of $\mathrm{Rg} 1$ treatment. In our study, the proteomic analysis showed that Rg1 treatment altered the expression of hippocampal proteins in 3xTg$\mathrm{AD}$ mice. According to the molecular functions and biological processes, these differentially expressed proteins were mainly involved in synaptic transmission, glycolytic process, response to stress, and regulation of apoptotic process. In the following sections, we focused on the discussion of those differentially expressed proteins associated with memory and depression.

4.1. Differentially Expressed Proteins in 3xTg-AD Mice Compared to WT Mice. SYN2, a synaptic vesicle protein, played an important role in neurotransmitter release [42]. The expression of SYN2 was significantly decreased in AD patients [43]. Besides, several studies showed that SYN2 knockout mice displayed obvious cognitive impairment. In combination with our data that the expression of SYN2 was significantly downregulated in $3 \mathrm{xTg}-\mathrm{AD}$ mice compared with the WT mice, these data indicated an involvement of SYN2 in the regulation of brain functions [44-46]. Though the SYN2 protein was not screened in 3xTg-AD mice with or without Rg1 treatment, the results of Western blot showed that Rg1 treatment significantly altered the expression of SYN2 in 3xTg-AD mice. Thus, it is suggested that Rg1 may exert the protective effects against memory impairment via upregulating the expression of SYN2 in the hippocampus of 3xTg-AD mice.

4.2. Differentially Expressed Proteins in 3xTg-AD Mice with or without Rg1 Treatment. SNP25, an important marker of functional synapses, was one of the major proteins involved in the formation of neural soluble N-ethylmaleimidesensitive factor attachment protein receptor (SNARE) complex [47]. The SNARE complex had a pivotal effect on the central nervous system and was also essential for learning and memory formation [48]. Studies showed that the expression of SNP25 was significantly downregulated in AD brains $[49,50]$. In addition, SNP25 expression change was also observed in other forms of dementia, such as vascular and frontotemporal dementia $[51,52]$. SNP25 played a vital role in spatial memory ability via regulating glutamatedependent excitatory transmission $[53,54]$. In this study, we found that the expression of SNP25 was significantly decreased in the hippocampus of 3xTg-AD mice compared with the WT mice, while Rg1 treatment could significantly modulate the expression of this protein and alleviate memory impairment of 3xTg-AD mice, suggesting an involvement of SNP25 in memory impairment of 3xTg-AD mice as observed and the protective effects of $\mathrm{Rg} 1$ on memory.

CPLX2 was a protein modulator of neurotransmitter release that was downregulated in patients suffering from depression [55]. As a cytosolic protein, a significant change of CPLX2 expression was observed in multiple neurological 
disorders such as depression [56, 57]. Besides, CPLX-2 knockout mice displayed cognitive disorder [58] and selective impairment in long-term potentiation (LTP) [59]. In our study, we found that the expression of CPLX2 was significantly decreased in $3 \times \mathrm{Tg}$ - $\mathrm{AD}$ mice compared with the WT mice and modulated by the treatment of Rg1, suggesting an involvement of CPLX2 in behavioral impairment of 3xTg-AD mice and the protective effects of Rg1 on memory and depression.

4.3. Summary. As displayed in Figure 9, our current data demonstrated that $\operatorname{Rg} 1$ could improve memory impairment and depression-like behavior of 3xTg-AD mice and modulate the expression of multiple proteins in the hippocampus. According to the biological function, these differentially expressed proteins were classified into the following 5 categories: synaptic transmission-related proteins, glycolytic process-related proteins, response to stress-related proteins, apoptotic process-related proteins, and other proteins. Importantly, CPLX2, a depression- and memory-related protein, and SYN2 and SNP25, two memory-related proteins, were significantly downregulated in the hippocampus of $3 \mathrm{xTg}-\mathrm{AD}$ mice, while the expression of these proteins was significantly modulated by the treatment of Rg1 treatment. These data suggested that Rg1 could be used as a potential candidate drug to improve the behavioral deficits in $\mathrm{AD}$ via modulating the expression of the proteins (i.e., CPLX2, SYN2, and SNP25) involved in memory and depression behaviors.

\section{Conflicts of Interest}

The authors declare that they have no conflict of interest to disclose.

\section{Authors' Contributions}

Lulin Nie and Junxia Xia contributed equally to this work.

\section{Acknowledgments}

This work was supported by the National Natural Science Foundation of China (81673134, 31670360), Guangdong Provincial Natural Science Foundation (2014A030313715, 2016A030313051), Guangdong Provincial Scheme of Science and Technology (to Xifei Yang), Initiating Grant for Overseas Study of Educational Ministry (0211510025), and Shenzhen Special Fund Project on Strategic Emerging Industry Development (JCYJ20160428143433768, JCYJ201 50529164656093, JCYJ20150529153646078, JCYJ20140416 122811964, JCYJ20160422143433757, CXZZ201505291651 10750, and ZDSYS201506031617582).

\section{References}

[1] J. Zhang, S. An, W. Hu et al., "The neuroprotective properties of Hericium erinaceus in glutamate-damaged differentiated PC12 cells and an Alzheimer's disease mouse model," International Journal of Molecular Sciences, vol. 17, no. 11, article E1810, 2016.
[2] C. H. Chang, Y. Chen, X. X. Yew et al., "Improvement of erinacine a productivity in Hericium erinaceus mycelia and its neuroprotective bioactivity against the glutamate-insulted apoptosis," LWT - Food Science and Technology, vol. 19, no. 6, pp. 616-626, 2015.

[3] A. C. Herrera, M. Prince, M. Knapp, M. Guerchet, and M. Karagiannidou, "World Alzheimer Report 2016: improving healthcare for people with dementia. Coverage, quality and costs now and in the future," Alzheimer's Disease International, 2016.

[4] J. Ruzicka, M. Kulijewicz-Nawrot, J. J. Rodrigez-Arellano, P. Jendelova, and E. Sykova, "Mesenchymal stem cells preserve working memory in the $3 \mathrm{xTg}-\mathrm{AD}$ mouse model of Alzheimer's disease," International Journal of Molecular Sciences, vol. 17, no. 2, article E152, 2016.

[5] M. O. Grimm, J. Mett, and T. Hartmann, "The impact of vitamin E and other fat-soluble vitamins on Alzheimer's disease," International Journal of Molecular Sciences, vol. 17, no. 11, article E1785, 2016.

[6] D. J. Selkoe, "Cell biology of protein misfolding: the examples of Alzheimer's and Parkinson's diseases," Nature Cell Biology, vol. 6, no. 11, pp. 1054-1061, 2004.

[7] R. O. Roberts, T. J. Christianson, W. K. Kremers et al., "Association between olfactory dysfunction and amnestic mild cognitive impairment and Alzheimer disease dementia," JAMA Neurology, vol. 73, no. 1, pp. 93-101, 2016.

[8] T. Sugimoto, R. Ono, S. Murata et al., "Prevalence and associated factors of sarcopenia in elderly subjects with amnestic mild cognitive impairment or Alzheimer disease," Current Alzheimer Research, vol. 13, no. 6, pp. 718-726, 2016.

[9] J. K. Chung, E. Plitman, S. Nakajima et al., "Cortical amyloid $\beta$ deposition and current depressive symptoms in Alzheimer disease and mild cognitive impairment," Journal of Geriatric Psychiatry and Neurology, vol. 29, no. 3, pp. 149-159, 2016.

[10] M. I. Geerlings, T. den Heijer, P. J. Koudstaal, A. Hofman, and M. M. Breteler, "History of depression, depressive symptoms, and medial temporal lobe atrophy and the risk of Alzheimer disease," Neurology, vol. 70, no. 15, pp. 1258-1264, 2008.

[11] J. T. Zhang, C. F. Chen, and G. Z. Liu, "The chemistry metabolism and biological activities of ginseng," Chemical Industry, vol. 16, no. 24, pp. 7841-7852, 2006.

[12] I. H. Cho, "Effects of Panax ginseng in neurodegenerative diseases," Journal of Ginseng Research, vol. 36, no. 4, pp. 342-353, 2012.

[13] N. Li, L. Zhou, W. Li, Y. Liu, J. Wang, and P. He, "Protective effects of ginsenosides Rg1 and Rb1 on an Alzheimer's disease mouse model: a metabolomics study," Journal of Chromatography $B$, vol. 985, pp. 54-61, 2015.

[14] I. Mook-Jung, H. S. Hong, J. H. Boo et al., "Ginsenoside Rb1 and Rg1 improve spatial learning and increase hippocampal synaptophysin level in mice," Journal of Neuroscience Research, vol. 63, no. 6, pp. 509-515, 2001.

[15] Y. Q. Shi, T. W. Huang, L. M. Chen et al., "Ginsenoside Rg1 attenuates amyloid- $\beta$ content, regulates PKA/CREB activity, and improves cognitive performance in SAMP8 mice," Journal of Alzheimer's Disease, vol. 19, no. 3, pp. 977-989, 2010.

[16] F. Fang, X. Chen, T. Huang, L. F. Lue, J. S. Luddy, and S. S. Yan, "Multi-faced neuroprotective effects of ginsenoside Rg1 in an Alzheimer mouse model," Biochimica et Biophysica Acta (BBA) - Molecular Basis of Disease, vol. 1822, no. 2, pp. 286292, 2012. 
[17] Q. Quan, J. Wang, X. Li, and Y. Wang, "Ginsenoside Rg1 decreases $\mathrm{A} \beta_{1-42}$ level by upregulating $\operatorname{PPAR} \gamma$ and IDE expression in the hippocampus of a rat model of Alzheimer's disease," PLoS One, vol. 8, no. 3, article e59155, 2013.

[18] L. Gong, S. L. Li, H. Li, and L. Zhang, "Ginsenoside Rg1 protects primary cultured rat hippocampal neurons from cell apoptosis induced by $\beta$-amyloid protein," Pharmaceutical Biology, vol. 49, no. 5, pp. 501-507, 2011.

[19] Q. Liu, J. P. Kou, and B. Y. Yu, "Ginsenoside Rg1 protects against hydrogen peroxide-induced cell death in PC12 cells via inhibiting NF- $\kappa \mathrm{B}$ activation," Neurochemistry International, vol. 58, no. 1, pp. 119-125, 2011.

[20] J. K. Clark, M. Furgerson, J. D. Crystal, M. Fechheimer, R. Furukawa, and J. J. Wagner, "Alterations in synaptic plasticity coincide with deficits in spatial working memory in presymptomatic 3xTg-AD mice," Neurobiology of Learning and Memory, vol. 125, pp. 152-162, 2015.

[21] A. Romano, L. Pace, B. Tempesta et al., "Depressive-like behavior is paired to monoaminergic alteration in a murine model of Alzheimer's disease," International Journal of Neuropsychopharmacology, vol. 18, no. 4, article pyu020, 2014.

[22] X. Y. Song, J. F. Hu, S. F. Chu et al., "Ginsenoside Rg1 attenuates okadaic acid induced spatial memory impairment by the GSK $3 \beta /$ tau signaling pathway and the $\mathrm{A} \beta$ formation prevention in rats," European Journal of Pharmacology, vol. 710, no. 1-3, pp. 29-38, 2013.

[23] L. Prut and C. Belzung, "The open field as a paradigm to measure the effects of drugs on anxiety-like behaviors: a review," European Journal of Pharmacology, vol. 463, no. 1-3, pp. 333, 2003.

[24] C. Belzung and G. Griebel, "Measuring normal and pathological anxiety-like behaviour in mice: a review," Behavioural Brain Research, vol. 125, no. 1-2, pp. 141-149, 2001.

[25] L. Steru, R. Chermat, B. Thierry, and P. Simon, "The tail suspension test: a new method for screening antidepressants in mice," Psychopharmacology, vol. 85, no. 3, pp. 367-370, 1985.

[26] Y. Deng-Bryant, L. Y. Leung, K. Caudle, F. Tortella, and D. Shear, "Cognitive evaluation using Morris water maze in neurotrauma," Methods in Molecular Biology, vol. 1462, pp. 539-551, 2016.

[27] S. Iadevaia, Y. Lu, F. C. Morales, G. B. Mills, and P. T. Ram, "Identification of optimal drug combinations targeting cellular networks: integrating phospho-proteomics and computational network analysis," Cancer Research, vol. 70, no. 17, pp. 6704$6714,2010$.

[28] E. Orta-Salazar, A. Feria-Velasco, G. I. Medina-Aguirre, and S. Díaz-Cintra, "Morphological analysis of the hippocampal region associated with an innate behaviour task in the transgenic mouse model (3xTg-AD) for Alzheimer disease," Neurología, vol. 28, no. 8, pp. 497-502, 2013.

[29] S. Chakroborty, J. Kim, C. Schneider, C. Jacobson, J. Molgó, and G. E. Stutzmann, "Early presynaptic and postsynaptic calcium signaling abnormalities mask underlying synaptic depression in presymptomatic Alzheimer's disease mice," Journal of Neuroscience, vol. 32, no. 24, pp. 8341-8353, 2012.

[30] H. J. Kim, P. Kim, and C. Y. Shin, "A comprehensive review of the therapeutic and pharmacological effects of ginseng and ginsenosides in central nervous system," Journal of Ginseng Research, vol. 37, no. 1, pp. 8-29, 2013.

[31] B. Jiang, Z. Xiong, J. Yang et al., “Antidepressant-like effects of ginsenoside Rg1 are due to activation of the BDNF signalling pathway and neurogenesis in the hippocampus," British Journal of Pharmacology, vol. 166, no. 6, pp. 18721887, 2012.

[32] E. J. Huang and L. F. Reichardt, "Neurotrophins: roles in neuronal development and function," Annual Review of Neuroscience, vol. 24, no. 1, pp. 677-736, 2001.

[33] G. Zhu, Y. Wang, J. Li, and J. Wang, "Chronic treatment with ginsenoside Rgl promotes memory and hippocampal longterm potentiation in middle-aged mice," Journal of Neuroscience, vol. 292, pp. 81-89, 2015.

[34] C. Sheng, W. Peng, Z. A Xia et al., "The impact of ginsenosides on cognitive deficits in experimental animal studies of Alzheimer's disease: a systematic review," BMC Complementary and Alternative Medicine, vol. 15, p. 386, 2015.

[35] C. Shi, D. D. Zheng, L. Fang, F. Wu, W. H. Kwong, and J. Xu, "Ginsenoside Rg1 promotes nonamyloidgenic cleavage of APP via estrogen receptor signaling to MAPK/ERK and PI3K/Akt," Biochimica et Biophysica Acta (BBA) - General Subjects, vol. 1820, no. 4, pp. 453-460, 2012.

[36] L. Yang, J. Zhang, K. Zheng, H. Shen, and X. Chen, "Long-term ginsenoside Rg1 supplementation improves age-related cognitive decline by promoting synaptic plasticity associated protein expression in C57BL/6J mice," Journals of Gerontology Series A: Biological Sciences and Medical Sciences, vol. 69, no. 3, pp. 282-294, 2014.

[37] I. Dewachter, J. Van Dorpe, L. Smeijers et al., “Aging increases amyloid peptides and causes plaques in brain of old APP/London transgenic mice by a different mechanism than a mutant presenilin-1 transgene," Neurobiology of Aging, vol. 20, no. 17, pp. 6452-6458, 2000.

[38] K. Yang, Y. Tan, F. Wang et al., "The improvement of spatial memory deficits in APP/V717I transgenic mice by chronic anti-stroke herb treatment," Experimental Biology and Medicine, vol. 239, no. 8, pp. 1007-1017, 2014.

[39] F. Li, X. Wu, J. Li, and Q. Niu, "Ginsenoside Rg1 ameliorates hippocampal long-term potentiation and memory in an Alzheimer's disease model," Molecular Medicine Reports, vol. 13, no. 6, pp. 4904-4910, 2016.

[40] X. Zhu, R. Gao, Z. Liu et al., "Ginsenoside Rg1 reverses stress-induced depression-like behaviours and brain-derived neurotrophic factor expression within the prefrontal cortex," European Journal of Neuroscience, vol. 44, no. 2, pp. 18781885, 2016.

[41] X. Zheng, Y. Liang, A. Kang et al., "Peripheral immunomodulation with ginsenoside Rg1 ameliorates neuroinflammationinduced behavioral deficits in rats," Neuroscience, vol. 256, pp. 210-222, 2014.

[42] L. Ho, Y. Guo, L. Spielman et al., "Altered expression of atype but not b-type synapsin isoform in the brain of patients at high risk for Alzheimer's disease assessed by DNA microarray technique," Neuroscience Letters, vol. 298, no. 3, pp. 191-194, 2001.

[43] C. A. Altar, M. P. Vawter, and S. D. Ginsberg, "Target identification for CNS diseases by transcriptional profiling," Neuropsychopharmacology, vol. 34, no. 1, pp. 18-54, 2009.

[44] A. Corradi, A. Zanardi, C. Giacomini et al., "Synapsin-I- and synapsin-II-null mice display an increased age-dependent cognitive impairment," Journal of Cell Science, vol. 121, Part 18, pp. 3042-3051, 2008.

[45] B. A. Dyck, K. J. Skoblenick, J. M. Castellano, K. Ki, N. Thomas, and R. K. Mishra, "Synapsin II knockout mice 
show sensorimotor gating and behavioural abnormalities similar to those in the phencyclidine-induced preclinical animal model of schizophrenia," Schizophrenia Research, vol. 97, no. 1-3, pp. 292-293, 2007.

[46] B. A. Dyck, K. J. Skoblenick, J. M. Castellano, K. Ki, N. Thomas, and R. K. Mishra, "Behavioral abnormalities in synapsin II knockout mice implicate a causal factor in schizophrenia," Synapse, vol. 63, no. 8, pp. 662-672, 2009.

[47] A. Brinkmalm, G. Brinkmalm, W. G. Honer et al., "SNAP-25 is a promising novel cerebrospinal fluid biomarker for synapse degeneration in Alzheimer's disease," Molecular Neurodegeneration, vol. 9, no. 1, p. 53, 2014.

[48] X. Zheng and J. A. Bobich, "A sequential view of neurotransmitter release," Brain Research Bulletin, vol. 47, no. 2, pp. 117-128, 1998.

[49] S. Zahid, R. Khan, M. Oellerich, N. Ahmed, and A. R. Asif, "Differential S-nitrosylation of proteins in Alzheimer's disease," Neuroscience, vol. 256, pp. 126-136, 2014.

[50] S. Shimohama, S. Fujimoto, Y. Sumida et al., "Differential expression of rat brain synaptic proteins in development and aging," Biochemical and Biophysical Research Communications, vol. 251, no. 1, pp. 394-398, 1998.

[51] A. Savioz, B. M. Riederer, P. Heutink et al., "Tau and neurofilaments in a family with frontotemporal dementia unlinked to chromosome 17q21-22," Neurobiology of Disease, vol. 12, no. 1, pp. 46-55, 2003.

[52] L. I. Sinclair, H. M. Tayler, and S. Love, "Synaptic protein levels altered in vascular dementia," Neuropathology and Applied Neurobiology, vol. 41, no. 4, pp. 533-543, 2015.

[53] A. G. McKee, J. S. Loscher, N. C. O'Sullivan et al., "AAVmediated chronic over-expression of SNAP-25 in adult rat dorsal hippocampus impairs memory-associated synaptic plasticity," Journal of Neurochemistry, vol. 112, no. 4, pp. 991-1004, 2010.

[54] G. Chen, T. Hu, Q. Li, J. Li, Y. Jia, and Z. Wang, "Expression of synaptosomal-associated protein-25 in the rat brain after subarachnoid hemorrhage," Neural Regeneration Research, vol. 8, no. 29, pp. 2693-2702, 2013.

[55] D. Glynn, H. E. Gibson, M. K. Harte et al., "Clorgyline-mediated reversal of neurological deficits in a complexin 2 knockout mouse," Human Molecular Genetics, vol. 19, no. 17, pp. 34023412, 2010.

[56] S. L. Eastwood and P. J. Harrison, "Synaptic pathology in the anterior cingulate cortex in schizophrenia and mood disorders. A review and a Western blot study of synaptophysin, GAP-43 and the complexins," Brain Research Bulletin, vol. 55, no. 5, pp. 569-578, 2001.

[57] K. Sawada, C. E. Young, A. M. Barr et al., "Altered immunoreactivity of complexin protein in prefrontal cortex in severe mental illness," Molecular Psychiatry, vol. 7, no. 5, pp. 484492, 2002.

[58] H. T. McMahon, M. Missler, C. Li, and T. C. Südhof, "Complexins: cytosolic proteins that regulate SNAP receptor function," Cell, vol. 83, no. 1, pp. 111-119, 1995.

[59] W. Freeman and A. J. Morton, "Regional and progressive changes in brain expression of complexin II in a mouse transgenic for the Huntington's disease mutation," Brain Research Bulletin, vol. 63, no. 1, pp. 45-55, 2004. 


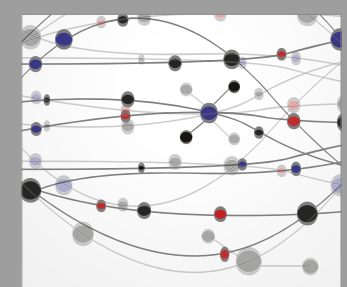

The Scientific World Journal
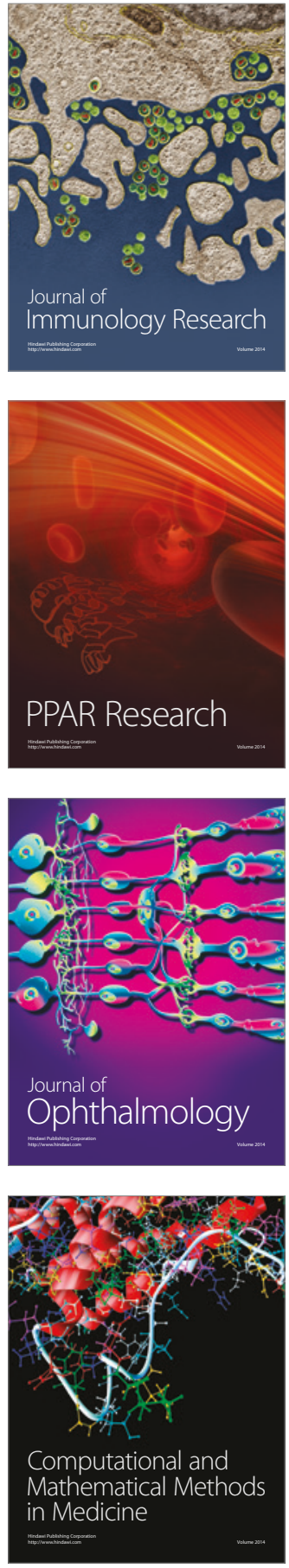

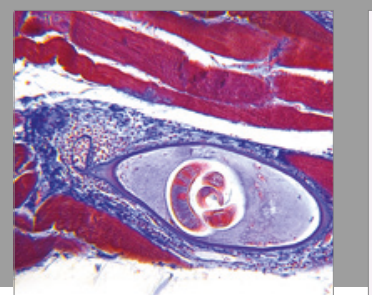

Gastroenterology Research and Practice
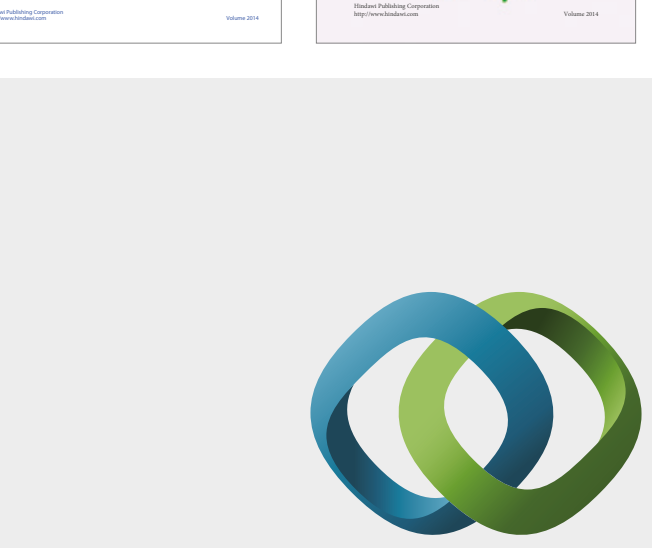

\section{Hindawi}

Submit your manuscripts at

https://www.hindawi.com
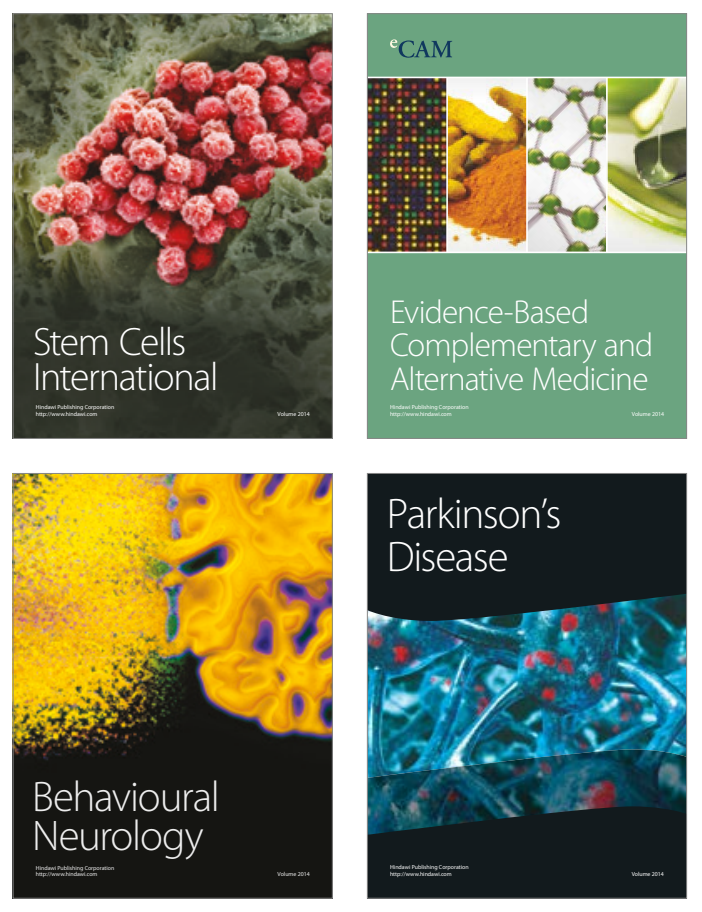
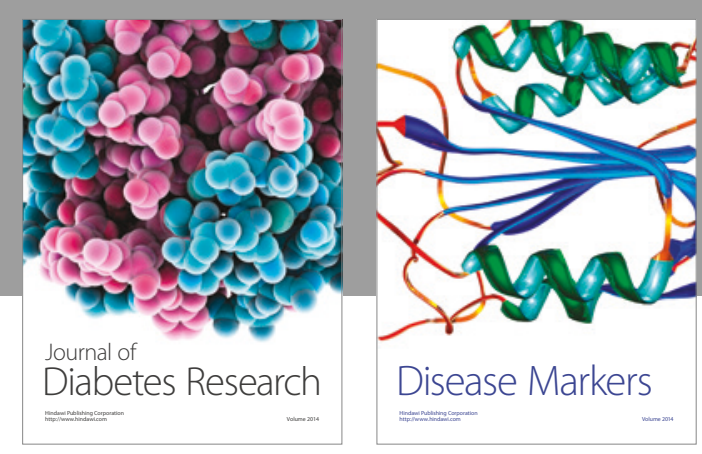

Disease Markers
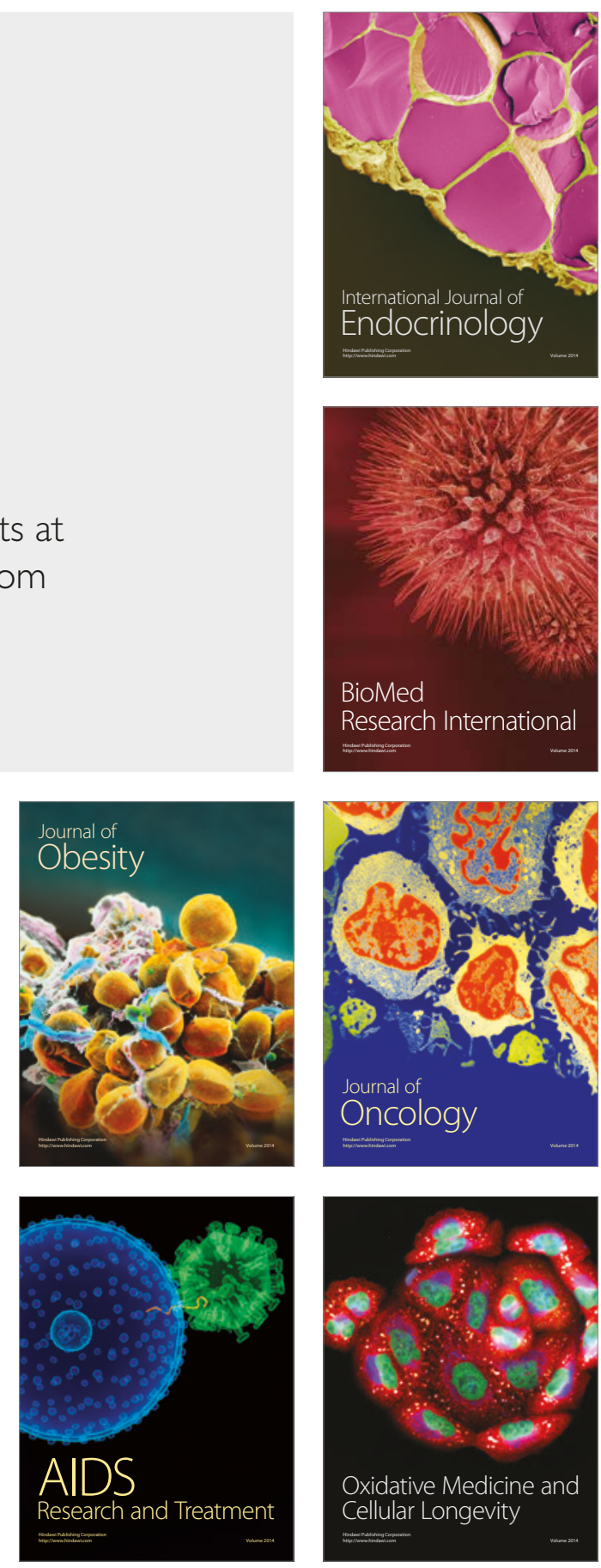